\title{
Cirrus Cloud Properties as Seen by the CALIPSO Satellite and ECHAM-HAM Global Climate Model ${ }^{\mathscr{a}}$
}

\author{
B. GASPARINI \\ ETH Zürich, Zürich, Switzerland
}

\author{
A. MEYER \\ Atmospheric Data Division, Federal Office of Meteorology and Climatology, MeteoSwiss, Payerne, Switzerland \\ D. Neubauer, S. Münch, And U. Lohmann \\ ETH Zürich, Zürich, Switzerland
}

(Manuscript received 17 August 2016, in final form 21 September 2017)

\begin{abstract}
Cirrus clouds impact the planetary energy balance and upper-tropospheric water vapor transport and are therefore relevant for climate. In this study cirrus clouds at temperatures colder than $-40^{\circ} \mathrm{C}$ simulated by the ECHAM-Hamburg Aerosol Module (ECHAM-HAM) general circulation model are compared to CloudAerosol Lidar and Infrared Pathfinder Satellite Observations (CALIPSO) satellite data. The model captures the general cloud cover pattern and reproduces the observed median ice water content within a factor of 2 , while extinction is overestimated by about a factor of 3 as revealed by temperature-dependent frequency histograms. Two distinct types of cirrus clouds are found: in situ-formed cirrus dominating at temperatures colder than $-55^{\circ} \mathrm{C}$ and liquid-origin cirrus dominating at temperatures warmer than $-55^{\circ} \mathrm{C}$. The latter cirrus form in anvils of deep convective clouds or by glaciation of mixed-phase clouds, leading to high ice crystal number concentrations. They are associated with extinction coefficients and ice water content of up to $1 \mathrm{~km}^{-1}$ and $0.1 \mathrm{~g} \mathrm{~m}^{-3}$, respectively, while the in situ-formed cirrus are associated with smaller extinction coefficients and ice water content. In situ-formed cirrus are nucleated either heterogeneously or homogeneously. The simulated homogeneous ice crystals are similar to liquid-origin cirrus, which are associated with high ice crystal number concentrations. On the contrary, heterogeneously nucleated ice crystals appear in smaller number concentrations. However, ice crystal aggregation and depositional growth smooth the differences between several formation mechanisms, making the attribution to a specific ice nucleation mechanism challenging.
\end{abstract}

\section{Introduction}

Cirrus clouds play an important role in Earth's radiation budget, atmospheric heat transport, water cycle, and the distribution of water vapor in the upper troposphere and lower stratosphere (Lohmann and Roeckner 1995; Chen et al. 2000; Hartmann et al. 2001; Stephens 2005; Randel and Jensen 2013). They scatter and absorb

Supplemental information related to this paper is available at the Journals Online website: https://doi.org/10.1175/JCLI-D-160608.s1.

Corresponding author: Blaž Gasparini, blaz.gasparini@env. ethz.ch both solar radiation and thermal radiation and emit radiation in the infrared part of the thermal spectrum. Depending on their temperature and optical thickness, but also on insolation and surface albedo, they can have a radiative heating or cooling effect on the surrounding air masses and the surface (Fusina et al. 2007; Corti and Peter 2009; Joos et al. 2014; Gasparini et al. 2017). Cirrus form when sufficiently moist air or water droplets are cooled to temperatures at which ice nucleation is possible. Moderate cooling with updraft velocities of several centimeters per second to tens of centimeters per second can take place in midlatitude cyclone warm conveyor belts (Spichtinger et al. 2005; Madonna 2014; Wernli et al. 2016) or in the cyclone's warm sector, ahead of a warm front (Field and Wood 
2007). Cirrus can also form in stronger updrafts (vertical velocities $>1 \mathrm{~m} \mathrm{~s}^{-1}$ ) in the outflow of thunderstorm clouds (Muhlbauer et al. 2014a) and in orographically forced ascent (Joos et al. 2008). Moreover, they can be initiated by high-frequency gravity waves, which play a large role in cirrus cloud formation (and dissipation) in the tropical tropopause layer (Spichtinger and Krämer 2013; Jensen et al. 2016; Dinh et al. 2016; Shi and Liu 2016). We define cirrus clouds as all clouds composed of ice crystals (ICs) at temperatures colder than $-40^{\circ} \mathrm{C}$, at cloud optical depth (COD) smaller than 3 , with an ice water content (IWC) larger than $0.05 \mathrm{mg} \mathrm{m}^{-3}$, including convective outflow clouds and glaciated mixed-phase clouds. We consider also the top layers of deep convective clouds, before their COD reaches the value of 3 .

Microphysically, cirrus clouds form by either homogeneous or heterogeneous nucleation. Homogeneous nucleation is a stochastic process of ice-germ formation in a supercooled liquid in the absence of an insoluble substance that provides a surface for ice nucleation to take place (Ickes et al. 2015). Micrometer-size water droplets freeze at about $-38^{\circ} \mathrm{C}$ and with relative humidities with respect to ice $\left(\mathrm{RH}_{\text {ice }}\right)$ of approximately $150 \%-170 \%$ (Koop et al. 2000).

Meanwhile, heterogeneous nucleation is the process of ice-germ formation at the surface of an insoluble ice nucleating particle (INP), which lowers the energy barrier required for ice nucleation (Hoose and Möhler 2012; Kanji et al. 2017). Cziczo et al. (2013) found mineral dust to be the most common INP in IC residuals sampled in cirrus clouds. Their aircraft measurements suggest heterogeneous nucleation as the dominant freezing mechanism in the atmosphere. INPs can nucleate ICs already at $\mathrm{RH}_{\text {ice }}$ of $110 \%-140 \%$ (Möhler et al. 2006, 2008), which can be well below the homogeneous freezing threshold. On the other hand, solution droplets frequently freeze homogeneously over mountain regions with strong updrafts caused by orographic waves (Gasparini and Lohmann 2016; Barahona et al. 2017), or in regions with low INP concentrations, for example, in high latitudes in winter (Storelvmo and Herger 2014; Mitchell et al. 2016).

Krämer et al. (2016) proposed a new cirrus classification based on the environment in which cirrus form. In situ cirrus clouds form at temperatures colder than $-38^{\circ} \mathrm{C}$ in the absence of liquid water and include both homogeneously and heterogeneously formed ICs. On the other hand, a large fraction of cirrus clouds have a liquid-phase history, particularly at temperatures warmer than $-60^{\circ} \mathrm{C}$ (Voigt et al. 2017; Wernli et al. 2016). Supercooled liquid droplets in strong convective updrafts or in warm conveyor belts of extratropical cyclones can freeze homogeneously once they cross the homogeneous freezing temperature limit. These clouds differ from in situ-formed cirrus in that they have higher IC number concentration, higher IWC, and larger ICs (Luebke et al. 2016). ICs can also be formed heterogeneously in the mixed-phase regime, allowing them to grow to larger sizes as result of a higher specific humidity at these warmer temperatures before they are advected to colder temperatures.

Historically, general circulation models (GCMs) used ice cloud properties as tuning parameters that helped models to achieve energy balance while representing reasonably well the other, more easily measurable climatic variables (Mauritsen et al. 2012). However, recent satellite observations (e.g., Rossow and Schiffer 1999; Li et al. 2012) put constraints on modeled cloud properties at a global scale. The past use of ice- and mixed-phase cloud properties as a tuning knob for the GCMs has produced the current large model spread of ice-phase properties. As an example, the IWC in CMIP3 and CMIP5 models spans over more than one order of magnitude with almost no model being able to fully reproduce satellite observations ( $\mathrm{Li}$ et al. 2012). Moreover, cirrus clouds are generally simulated in a highly simplified way in most state-of-the-art GCMs. To realistically simulate the ice phase, one needs to abandon the saturation adjustment for temperatures below the homogeneous freezing limit, to allow supersaturations with respect to ice (Lohmann and Kärcher 2002). The two microphysical pathways of in situ-formed cirrus clouds further represent a modeling challenge (Kärcher 2017). In addition, heterogeneous nucleation is dependent on modeled INP concentrations, which are highly uncertain in the upper troposphere (Koffi et al. 2016; Kanji et al. 2017). Large uncertainties call for extensive model verifications with both global satellite data and local in situ measurements. However, even currently available observational data cannot give conclusive answers about cirrus microphysical formation pathways on a global scale. As an example, instantaneous snapshots of cirrus capture clouds at different stages of their lifetimes from which it is difficult to infer the precise cirrus microphysics. This is where the models can help to deepen our process understanding by performing simulations with several levels of complexity of microphysical cirrus cloud formation as done in section 4 .

The objective of this study is to validate the microphysical properties of the cirrus clouds simulated by the global aerosol climate model ECHAM-Hamburg Aerosol Module (ECHAM-HAM) (Stevens et al. 2013; Zhang et al. 2012; Neubauer et al. 2014) and to better understand their formation pathways. We use a cirrus cloud climatology derived from the CALIPSO satellite for the validation. We first show a comparison 
of seasonal mean ice properties (section 3a) followed by a detailed investigation of in-cloud extinction coefficients (EXT) and IWC as a function of temperature and latitude (section 3b). Moreover, our study examines several cirrus formation pathways with the help of a model sensitivity study (section 4). In particular, we apply the same criterion to both the satellite and model data to distinguish in situ from liquid-origin cirrus clouds (section 4a).

\section{Cirrus cloud data}

\section{a. CALIOP lidar-CALIPSO-ST product}

The Cloud-Aerosol Lidar with Orthogonal Polarization (CALIOP) elastic backscatter lidar on board the CALIPSO satellite (Winker et al. 2010) has been collecting backscatter profiles at 532 and $1064 \mathrm{~nm}$ from particles suspended in the atmosphere since June 2006. The lidar is near-nadir pointing and provides measurements at a vertical resolution of $60 \mathrm{~m}$ and a horizontal resolution of $330 \mathrm{~m}$. Yet, we reduced the vertical resolution to $480 \mathrm{~m}$ to make it more comparable to the model's resolution. One CALIOP profile used in this study is an average of 15 backscatter profiles corresponding to a distance of $5 \mathrm{~km}$ along the 70-m-wide ground track.

CALIPSO orbits Earth about 16 times a day at an equatorial altitude of $705 \mathrm{~km}$ and a near-global coverage of $82^{\circ} \mathrm{N}-82^{\circ} \mathrm{S}$. It has a ground track repeat cycle of 16 days. Two adjacent ground tracks are separated by about $100 \mathrm{~km}$ in the midlatitudes. Thus, a $1.875^{\circ} \times 1.875^{\circ}$ grid box is passed over about 2-3 times a month in the midlatitudes.

The CALIOP backscatter detectors can obtain backscatter measurements over five orders of magnitude in order to detect backscatter from molecules, and aerosol and cloud particles (Winker et al. 2007, 2009). The CALIOP backscatter and depolarization measurements have been subjected to the CALIPSO level 2 retrieval algorithm in order to distinguish between clear-air, cloud, and aerosol particles (Young and Vaughan 2009; Vaughan et al. 2009). We examined seven years of nighttime measurements of particulate backscatter (January 2007-December 2013) based on the CALIPSOScience Team (ST) CALIOP level 2 cloud profile product, version 4 (Vaughan et al. 2016).

Misclassification of aerosol layers as cloud layers and vice versa is an important error source when calculating ice cloud occurrence frequencies derived from satellite measurements. We have filtered the backscatter measurements, analyzing only data with a cloud-aerosol discrimination score confidence level above 70 (Liu et al.
2009; Vaughan et al. 2009). We additionally eliminated uncertain measurements with the extinction QC 532 quality flag value larger than 7 (bits 4-9). We make use of temperature data from the Modern-Era Retrospective Analysis for Research and Applications, version 2 (MERRA-2), reanalysis product (Rienecker et al. 2011). To eliminate polar stratospheric cloud (PSC) pixels from our dataset, we have removed all backscatter measurements above $11-\mathrm{km}$ altitude poleward of $65^{\circ} \mathrm{N}$ and $65^{\circ} \mathrm{S}$. Day-night differences in cloud properties or abundance derived from CALIOP measurements may reflect actual differences, but they also could be a consequence of the lower daytime signal-tonoise ratio. Therefore, we evaluate nighttime measurements only, as they have the highest signal-to-noise ratios. We take $T=-40^{\circ} \mathrm{C}$ as the threshold temperature considered in our study in order to allow for the possibility of freezing point depressions in aqueous solution droplets. A measurement point/grid box from the CALIOP lidar is defined as cirrus cloud containing when an IC signal is present at temperatures colder than $-40^{\circ} \mathrm{C}$ and where the column COD has not exceeded 3. We discard measurement points with IWC $<$ $0.05 \mathrm{mg} \mathrm{m}^{-3}$, which is comparable to the estimate of CALIOP's level 2, version 3, nighttime IWC detection limit (Avery et al. 2012). Similarly, we define a column as cirrus cloud containing when an EXT and an IWC signal have been detected in any of the column's vertical levels.

\section{b. CALIOP lidar-CALIPSO-GOCCP product}

GCM-Oriented CALIPSO Cloud Product (GOCCP) is a dataset derived from the same CALIOP level 1 measured attenuated backscatter as the ST product (Chepfer et al. 2010). As GOCCP's main purpose is to evaluate cloud properties in GCMs, the vertical resolution is reduced from 60 to $480 \mathrm{~m}$. The dataset retains the full CALIPSO horizontal resolution of $330 \mathrm{~m}$. Its lidar profiles are averaged over a $2^{\circ} \times 2^{\circ}$ horizontal grid. The different horizontal averaging and cloud detection thresholds lead to significant cloud fraction disagreements between the GOCCP and ST datasets (Chepfer et al. 2013).

The GOCCP dataset simulator's definition of clouds has been implemented into the Cloud Feedback Model Intercomparison Project (CFMIP) Observational Simulator Package (COSP; Bodas-Salcedo et al. 2011; Chepfer et al. 2010). The simulator defines cloud cover from the model output equivalently to the one measured by the CALIPSO satellite. We use, unlike in the rest of the study, the standard COSP product output, where the cloud fraction is analyzed for both day and night data to compare it to the equivalent CALIPSO-GOCCP 
satellite dataset. GOCCP cloud occurrence is similar during day and night, while in the ST product it shows significant day-night differences (Chepfer et al. 2013). As GOCCP does not include IWC and EXT as its output variables, we focus on the CALIPSO-ST product throughout most of our study.

\section{c. Global aerosol-climate model ECHAM-HAM}

We use the Max Planck Institute for Meteorology general circulation model ECHAM6 (Stevens et al. 2013) coupled to the Hamburg Aerosol Module, version 2 (HAM2; Zhang et al. 2012). HAM2 contains a twomoment cloud microphysics scheme (Lohmann et al. 2007; Lohmann and Hoose 2009; Neubauer et al. 2014) coupled to a two-moment aerosol scheme (Vignati et al. 2004; Stier et al. 2005). The cirrus ice nucleation scheme is active at temperatures colder than $-35^{\circ} \mathrm{C}$, where all modeled supercooled liquid is transformed to ice. The scheme simulates the competition between homogeneous nucleation of solution droplets, immersion freezing of coated dust particles, deposition nucleation on uncoated dust particles, and depositional growth on preexisting ICs based on Kärcher et al. (2006). The homogeneous freezing parameterization is based on Koop et al. (2000), while the heterogeneous one is derived from Möhler et al. $(2006,2008)$ laboratory studies. The GCM implementation of the cirrus scheme is described in detail by Kuebbeler et al. (2014) and Gasparini and Lohmann (2016).

ECHAM-HAM uses the standard ECHAM model convective scheme for shallow, midlevel, and deep convection based on the mass flux scheme of Tiedtke (1989) with modifications described by Nordeng (1994) and Stevens et al. (2013). The convective scheme serves as a source of detrained vapor, liquid, and ice for the stratiform cloud scheme. The transported moisture flux is in the presence of existing stratiform cloud cover detrained in the form of condensed water or, in the case of sufficient preexisting ICs in a cloud, in the form of ice. The convective scheme detrains water vapor to grid boxes where the relative humidity is too low to allow cloud formation. The detrained IC radii are obtained from a temperature-dependent empirical relation (Boudala et al. 2002), while their number concentration is proportional to the detrained IWC over the cube of the effective radius.

An increase in lateral entrainment will typically decrease the buoyancy of the ascending air parcel and decrease the convective cloud-top height (Mauritsen et al. 2012). To represent clouds more realistically compared to satellite observation, we decreased the standard ECHAM6.1-HAM2.2 entrainment rates for both deep and shallow convection to $0.6 \times 10^{-4}$ and
$1.5 \times 10^{-3}$, respectively. This increased the level of detrainment and tropical cloudiness to values comparable to the GOCCP observational dataset while keeping the other climatic parameters in the range of the observations.

Moreover, the model's convective parameterization simulates a different type of convection for parcels that became unstable above the boundary layer, for example, as found in the warm sector of extratropical cyclones (Herzegh and Hobbs 1980; Tiedtke 1989). This so-called midlevel convection was found to be triggered too frequently in ECHAM-HAM (Isotta et al. 2011). We decreased its frequency by increasing the midlevel convective entrainment by an order of magnitude to $1 \times 10^{-3}$. At the same time, we increased the upper limit of midlevel convection from 400 to $200 \mathrm{hPa}$, improving the models' IC radius zonally averaged pattern, which was previously found to have caused an artificial peak just above the midlevel convective limit (not shown). However, even after the two adjustments, we note that midlevel convection in ECHAM-HAM is still triggered too often in regions where we would not expect it, for instance, over mountains and in the tropics (not shown).

In general, both in situ-formed and detrained freshly nucleated ICs are smaller than $20 \mu \mathrm{m}$; however, such particles rapidly grow by deposition, reaching sizes of $50 \mu \mathrm{m}$ and more. Moreover, a large proportion of convective ICs are quickly removed by aggregation of ICs and accretion from ice to snow, precipitating out from the atmosphere. In this study we transfer ICs to snow for ICs that exceed the aggregation threshold radius of $90 \mu \mathrm{m}$, which is within the range of other GCMs (Muhlbauer et al. 2014b).

The simulations were performed with the model version ECHAM6.1-HAM2.2 at a horizontal resolution of T63, corresponding to $1.875^{\circ} \times 1.875^{\circ}$, and 31 vertical layers extending to $10 \mathrm{hPa}$ with an average layer thickness of $700 \mathrm{~m}$ at typical cirrus altitudes. We simulated the period between 2007 and 2013 by using an AMIP style of simulation, using observed monthly sea surface temperatures and sea ice cover (Gates 1992), to be consistent with the CALIOP dataset. As previously discussed, we use only nighttime information in the model output; that is, we evaluate the model fields only at those grid points where the sun is below the horizon. As in CALIOP we also set the model's lower IWC detection threshold to $0.05 \mathrm{mg} \mathrm{m}^{-3}$.

All model-derived histograms are based on $7 \mathrm{yr}$ of 4-h instantaneous output values, except in the sensitivity study in section 4 , where the sampling of $1 \mathrm{yr}$ of model output is large enough to give robust cloud microphysical and radiative properties. 


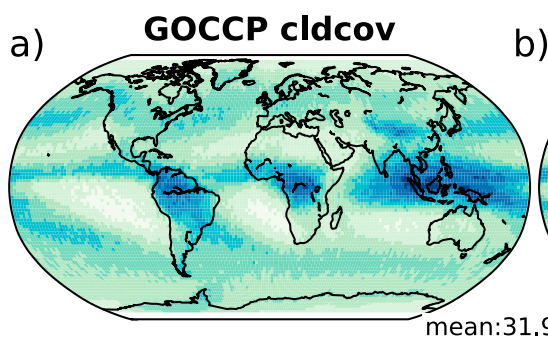

b)

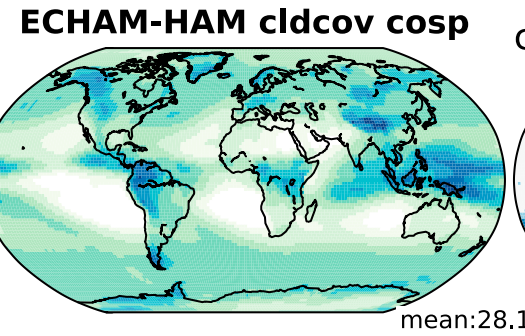

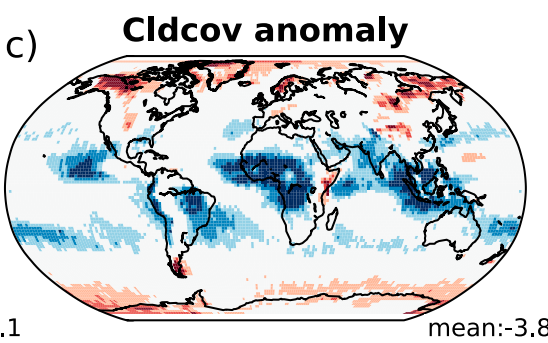
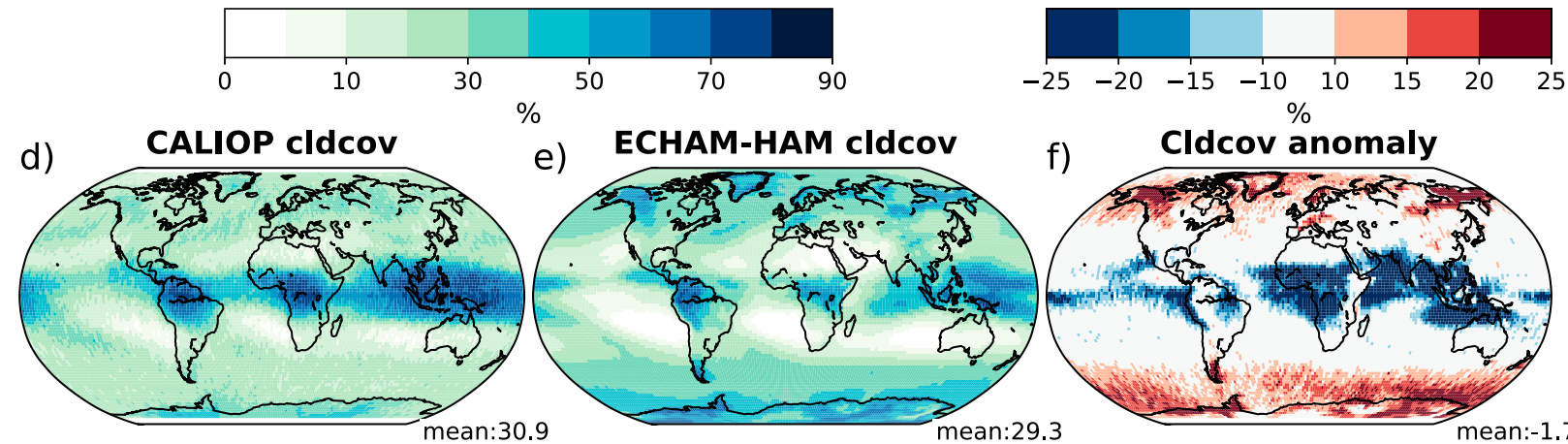

e)
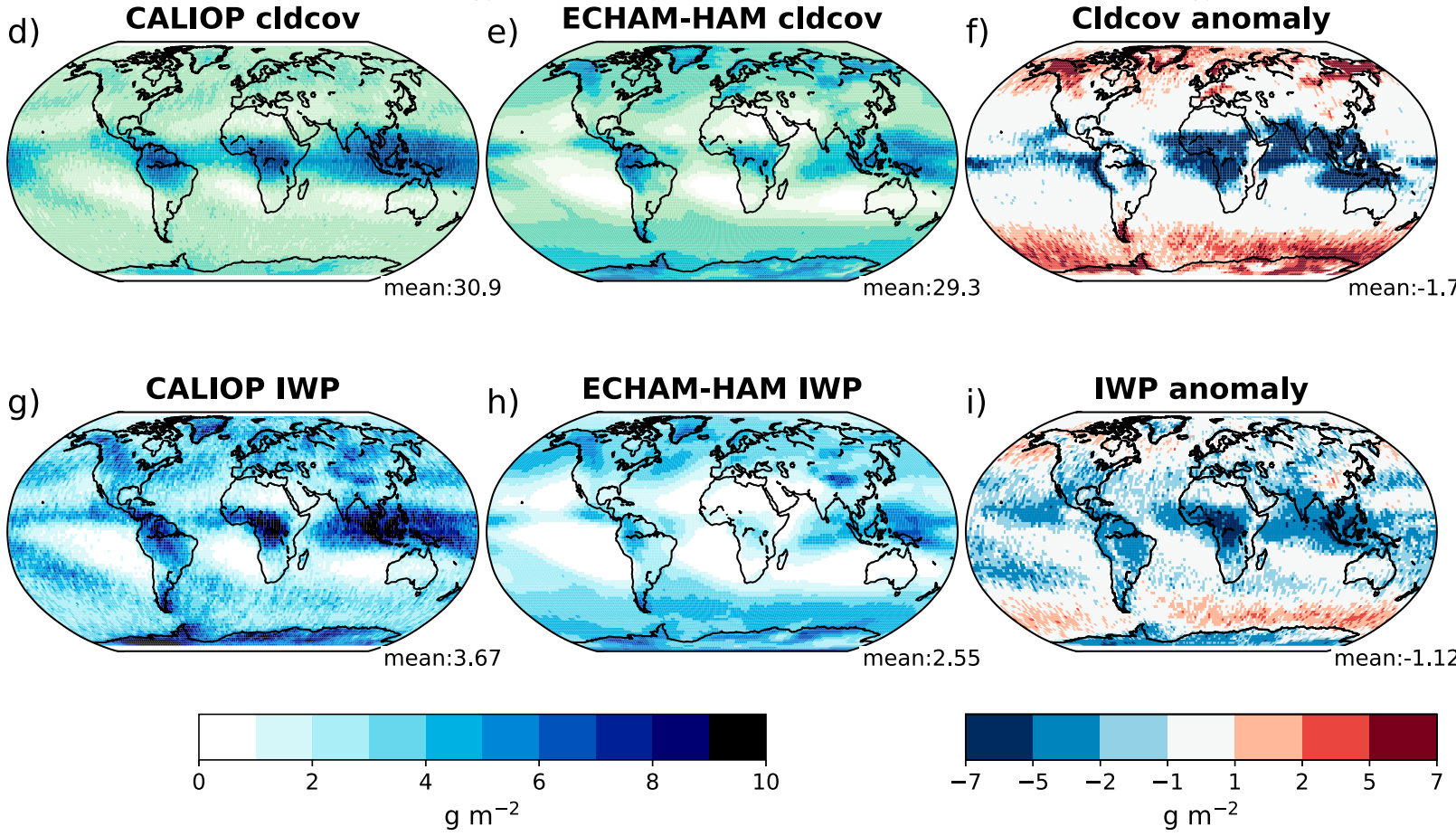

FIG. 1. Annually averaged cloud cover frequency for cirrus clouds with $T<-40^{\circ} \mathrm{C}$ from (a) CALIPSO-GOCCP and (d) CALIOP datasets with (b),(e) the corresponding ECHAM-HAM model outputs and (c),(f) the anomalies between the two. (g)-(i) The corresponding all-sky IWP. Numbers in the lower-right corner of each panel refer to global annual means.

\section{Results}

a. Mean values

\section{1) ICE OCCURRENCE FREQUENCIES}

We begin the comparison between the model output and satellite data by looking at high cloud cover from CALIPSO-GOCCP together with the model output processed by the COSP-CALIPSO satellite simulator. The high cloud definition in these two datasets depends only on the cloud altitude, not on temperature or the cloud phase: all clouds higher than $440 \mathrm{hPa}(6.6 \mathrm{~km})$ are considered as high, including the tropical mixed-phase clouds but excluding, for example, the Antarctic lower level ice clouds. The cloud data are averaged over the period between January 2007 and December 2013, considering both day and night measurements (Fig. 1a).

Figure $1 \mathrm{~b}$ shows the corresponding ECHAM-HAM high cloudiness, which in the global average reproduces well the satellite observations, simulating about $28 \%$ cirrus cloud cover in comparison to $32 \%$ retrieved from GOCCP. The most striking model bias is the lack of clouds over most of the tropics, with an anomaly of up to $20 \%-25 \%$ in some tropical land areas, which coincides with the model's low precipitation bias as a result of tooweak tropical land convection (Stevens et al. 2013). Part of the bias could also be due to a too-low number of INPs; however, that cannot be verified because of the 

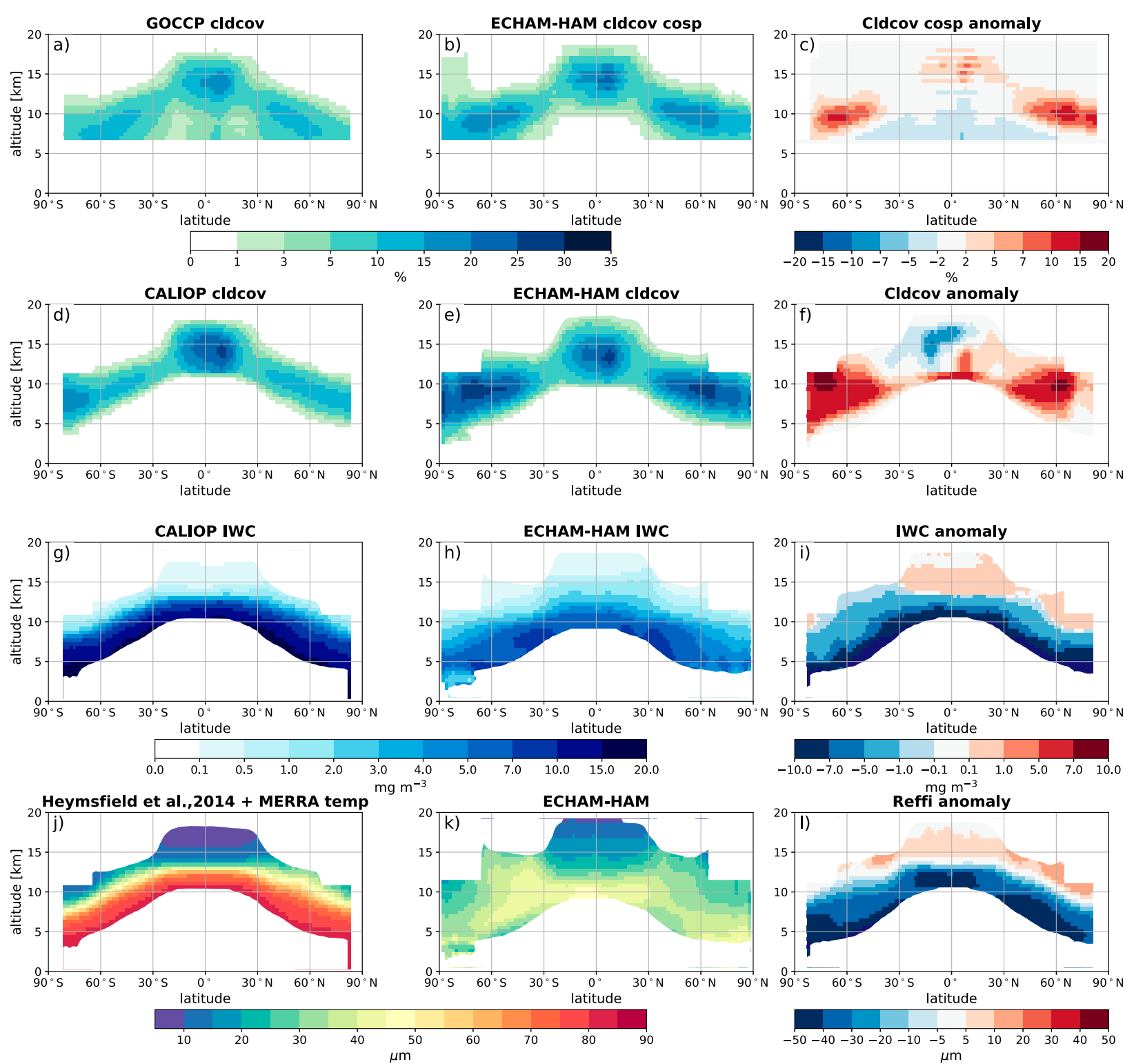

FIG. 2. Zonally averaged annual cloud cover frequency for the (a) GOCCP and (d) CALIOP datasets with (b),(e) the corresponding ECHAM-HAM model output and (c),(f) their anomaly, (g)-(i) in-cloud IWC, and (j)-(l) in-cloud IC effective radii.

lack of observations. On the other hand, the cloud cover is overestimated over most of regions poleward from $50^{\circ}$, possibly because of a too-frequently called midlevel convective scheme (Isotta et al. 2011; Gasparini 2016). Interestingly, the model seems to overestimate the cloud cover in orographic regions, where the subgrid-scale vertical velocity is enhanced by the orographic gravity waves (Joos et al. 2008).

The zonally averaged results in Figs. 2a-c confirm that the modeled altitude and latitude of peaks of high clouds are collocated with the observations. The ECHAMHAM's zonally averaged plot slightly overestimates the tropical cirrus cloud maximum, but it also shows that the model simulates about $5 \%-10 \%$ too many cirrus clouds in the mid- and high-latitude tropopause region (Fig. 1c). This is a known model bias, present in all standard resolution versions of the underlying ECHAM6 model (Cesana and Chepfer 2012), and is therefore not connected to the ECHAM-HAM's two-moment microphysics or cirrus schemes. The cloud cover bias is directly related to the relative humidity and temperature biases in the same region. Stevens et al. (2013) explained the presence of the bias by numerical diffusion resulting from coarse vertical resolution or the low model top, as the 
temperature bias vanished in the high-top and highresolution version of ECHAM6. Stenke et al. (2008) showed that about $50 \%$ of the temperature bias can be explained by the overestimation of water vapor concentrations.

Next, we use the CALIPSO-ST product, which is meant to represent clouds at the best possible resolution. As the signal-to-noise ratio is larger at the night, the detectability threshold can be lowered, allowing for the detection of clouds with a COD down to 0.005 , detecting an order of magnitude thinner clouds than with the GOCCP dataset (Chepfer et al. 2013). The difference in horizontal averaging of lidar backscatter measurements will additionally favor the detection of clouds in the ST product. A detailed analysis of the differences between the two products can be found in Chepfer et al. (2013).

The CALIPSO-ST product retrieves about the same amount of cirrus clouds in the global average as the GOCCP dataset (Figs. 1a,d). Part of the different pattern comes from a temperature-based, not altitude based, cirrus cloud criteria. The general pattern does not change significantly compared to GOCCP. Most notably, we observe a $10 \%-15 \%$ increase in tropical cirrus clouds, which is not surprising, as this is the preferential area of formation of the subvisible cirrus $(\mathrm{COD}<0.3$, Haladay and Stephens 2009; Lee et al. 2009), which are often not detected by the GOCCP algorithm. The cloud cover simulated by ECHAM-HAM and its anomalies following the temperature criteria do not change significantly (Figs. 1d, 2d).

Moreover, Figs. 2d-f show that the modeled cirrus clouds, defined by the temperature limit of $-40^{\circ} \mathrm{C}$, are present already below $10-\mathrm{km}$ altitude, or about $1-2 \mathrm{~km}$ lower than in the CALIOP dataset, which can be explained by the lower in-cloud temperature of the modeled cirrus clouds compared with the MERRA-2 temperatures ancillary to the CALIOP measurements (Fig. S1a in the supplemental information).

\section{2) ICE WATER PATH AND ICE WATER CONTENT}

The global average all-sky cirrus ice water path (IWP) is $3.7 \mathrm{~g} \mathrm{~m}^{-2}$ for the CALIPSO-ST product and accounts for only a small fraction of the global total nonprecipitating IWP of about $25 \mathrm{~g} \mathrm{~m}^{-2}$ as estimated from satellite data by Li et al. (2012). We define IWP as the vertically integrated IWC averaged over both cloudy and clear-sky scenes.

The CALIOP-derived IWC $\left(\mathrm{g} \mathrm{m}^{-3}\right)$ is related to the CALIOP ice cloud extinction $\varepsilon\left(\mathrm{km}^{-1}\right)$ by

$$
\mathrm{IWC}=\varepsilon(0.91 / 3) D_{e},
$$

where $D_{e}$ represents the IC effective diameter and is parameterized based on reanalysis temperature as

$$
D_{e}=\alpha e^{\beta T},
$$

where the parameters $\alpha$ and $\beta$ vary based on the temperature as described in Eq. (9e) of Heymsfield et al. (2014). They derived the parameterization from in situ (aircraft)measured particle shape distributions and IWCs, from which they computed the values of EXT. The temperaturedependent Heymsfield et al. (2014) parameterization for IC radii is shown in Fig. S2 of the supplemental information.

CALIOP-derived IWC peaks in the tropics, particularly over the warm pool area, tropical Africa, and South America, with maxima of about $10 \mathrm{~g} \mathrm{~m}^{-2}$ (Figs. 1e,f). Secondary maxima associated with the storm tracks do not exceed $6 \mathrm{~g} \mathrm{~m}^{-2}$. IWP is also peaking over mountain regions driven by orographic wave forcing, in particular over the Rocky Mountains, the Andes, the Antarctic Peninsula, Greenland, and the Himalayas. Cirrus clouds in ECHAM-HAM, on the other hand, contain on average about $30 \%$ less IWP than estimates from satellite data. The simulated cirrus have a low IWP bias in the tropics and in parts of midlatitudes, while IWP in the Southern Ocean and in parts of the Arctic roughly follows the biases in cloud cover (Fig. 1i).

The zonally averaged mean in-cloud IWC in Figs. 2g-i shows a negative bias below about $12 \mathrm{~km}$ in the tropics and over most of the extratropics, and a positive bias in the uppermost tropical troposphere. It is particularly pronounced in the lowermost considered levels, where the model simulates about 2-3 times smaller mean IWC values compared to CALIPSO observations. The bias can be explained by particle size disagreements (section 2) and ECHAM-HAM's upper-tropospheric temperature biases (Fig. S1). In addition, at the warmest considered temperatures we expect part of the IWC to be in the form of precipitating snow, which has been excluded from this study. However, because of the typically very skewed IWP distribution in regions dominated by tropical convection, a disagreement in mean IWC values does not necessarily translate into a radiative bias, as the median is a better single descriptor of the IWC distribution (Berry and Mace 2014).

\section{3) ICE CRYSTAL EFFECTIVE RADIUS}

The IC radius, needed for deriving IWC [Eq. (1)], is parameterized in CALIOP, version 4 , as a function of the MERRA-2 reanalysis temperature (Rienecker et al. 2011; Fig. S2). The radii values are therefore subject to uncertainties from the reanalysis temperatures and the Heymsfield et al. (2014) parameterization. The mean IC effective radius from Heymsfield et al. (2014) ranges from about 65 to $85 \mu \mathrm{m}$ for the warmest cirrus clouds (temperature range between $-40^{\circ}$ and $-55^{\circ} \mathrm{C}$; Figs. $2 \mathrm{j}$ and $\mathrm{S} 2$ ), as obtained mainly from tropical detrained cirrus. 
The parameterization is therefore likely overestimating the IC size in the extratropics, where the frequency of convective and other liquid-origin cirrus is smaller (Heymsfield et al. 2017b). The IC size quickly decreases to approximately $10 \mu \mathrm{m}$ in the temperature range between $-55^{\circ}$ and $-70^{\circ} \mathrm{C}$. However, the Heymsfield et al. (2014) dataset is based on a considerably smaller data sample for the temperatures colder than $-60^{\circ} \mathrm{C}$ compared to the warmer temperature range and is therefore less reliable in the cold temperature range (Heymsfield et al. 2017a).

ECHAM-HAM, on the other hand, simulates considerably smaller IC radii in warm cirrus clouds, with radii of about $35-50 \mu \mathrm{m}$ as shown in Figs. $2 \mathrm{k}$ and S2. Not surprisingly, the general pattern of the model's IWC anomalies is similar (though less pronounced) to the IC radii anomalies. However, the model simulates IC radii in the range between 10 and $25 \mu \mathrm{m}$ close to the tropopause levels, which is larger compared to Heymsfield et al. (2014; Fig. 21). We leave a detailed IC radius comparison to further studies, as the main focus of this study is related to the CALIPSO satellite product.

\section{b. Instantaneous fields}

Annually averaged mean values often do not provide the most complete or accurate view of cloud properties. Therefore, we compare instantaneous CALIOP data and model output to study cirrus cloud EXT and IWC as a function of temperature. The 4-hourly ECHAMHAM nighttime data are obtained from a period between January 2007 and December 2013, to ensure consistency with the considered 7-yr CALIOP dataset. We divide the planet into three geographical regions, defined as follows:

- tropics between $30^{\circ} \mathrm{N}$ and $30^{\circ} \mathrm{S}$,

- midlatitudes, between $30^{\circ}$ and $67^{\circ}$ in both hemispheres, and

- high latitudes, poleward from $67^{\circ}$ in both hemispheres.

As ECHAM-HAM has relatively large vertical model layer thickness of 500-1000 m at typical cirrus cloud altitudes, we divided the model output and the satellite dataset in 10 equispaced bins of $5^{\circ} \mathrm{C}$ each. The $5^{\circ} \mathrm{C}$ binning step is a good compromise between the coarse model's resolution and the fine satellite's resolution. The lapse rate at temperatures colder than $-40^{\circ} \mathrm{C}$ is close to $9^{\circ} \mathrm{C} \mathrm{km}^{-1}$ (where the model's vertical resolution is close to $500 \mathrm{~m}$ ) and decreases to lower values in the tropopause region (where the model resolution is coarser).

We compare CALIOP and ECHAM-HAM EXT and IWC in 2D histograms as a function of temperature for the three regions. The histograms are divided in equispaced bins in logarithmic space for quantities plotted on the $x$ axis (EXT and IWC) with temperature plotted on the $y$ axis. We normalize the data such that the total sum of the frequencies in all bins is equal to 1 . We note that the high-latitude signal is heavily dominated by wintertime/polar night values.

\section{1) EXTINCTION COEFFICIENTS AT $532 \mathrm{NM}$}

The cirrus cloud EXT are directly related to the CALIOP backscatter measurements and thus are the most direct CALIOP-derived quantity used in this study (Young and Vaughan 2009; Garnier et al. 2015). EXT quantifies the attenuation of light at $532 \mathrm{~nm}$ by scattering and absorption from ice particles according to the Beer-Lambert law. We derived instantaneous model output from the radiation routine for the band between 442 and $625 \mathrm{~nm}$, with a mid-wavelength of $525 \mathrm{~nm}$. We do not expect significant differences because of the band differences between the two datasets (Segal-Rosenheimer et al. 2013). In general, CALIOP EXT values range between around $10^{-3}$ and $10 \mathrm{~km}^{-1}$ with median values between 0.02 and $0.12 \mathrm{~km}^{-1}$ (Fig. 3a). The model, however, simulates about 2-4 times higher EXT (Figs. 3b,c), with its median ranging between $0.05 \mathrm{~km}^{-1}$ for the coldest and $0.4 \mathrm{~km}^{-1}$ for the warmest examined temperatures. The cause of ECHAMHAM's bias is the IC radius, which is smaller than the one measured in situ by Heymsfield et al. (2014).

The EXT signal does not vary much between mid- and high latitudes (Figs. 3d-i) in both satellite and model data. It shows a peak between 0.1 and $1 \mathrm{~km}^{-1}$ at temperatures colder than $-55^{\circ} \mathrm{C}$, while the model simulates significantly higher EXT. We relate the frequency distribution peaks observed by Luebke et al. (2013) to the thicker liquid-origin cirrus on the one hand and the thinner and colder in situ-formed cirrus on the other hand, as discussed in detail in section 4 .

Finally, in the tropics the CALIOP signal peaks with a pronounced high-frequency "hat" at temperatures between $-75^{\circ}$ and $-85^{\circ} \mathrm{C}$ sitting on top of a narrower temperature-dependent distribution. The narrower stripe of high likelihood EXT is probably associated with deep convective activity, which directly or indirectly contributes to most of the tropical cirrus cloud cover (Luo and Rossow 2004). This peak extends to EXT between $5 \times 10^{-1}$ and $1 \mathrm{~km}^{-1}$ at temperatures between $-40^{\circ}$ and $-70^{\circ} \mathrm{C}$. The broader tropical tropopause frequency hat has EXT from $10^{-3}$ and $0.1 \mathrm{~km}^{-1}$. This signal is a mixture of the in situ-formed subvisible tropical cirrus clouds and the anvil edges of the strong tropical convection. The EXT values are consistent with the in situ measurements by Lawson et al. (2008) and Jensen et al. (2016), but they are larger than those observed by Tropical Composition, Cloud and Climate Coupling (TC4) field campaign measurements (Davis 


\section{Extinction}
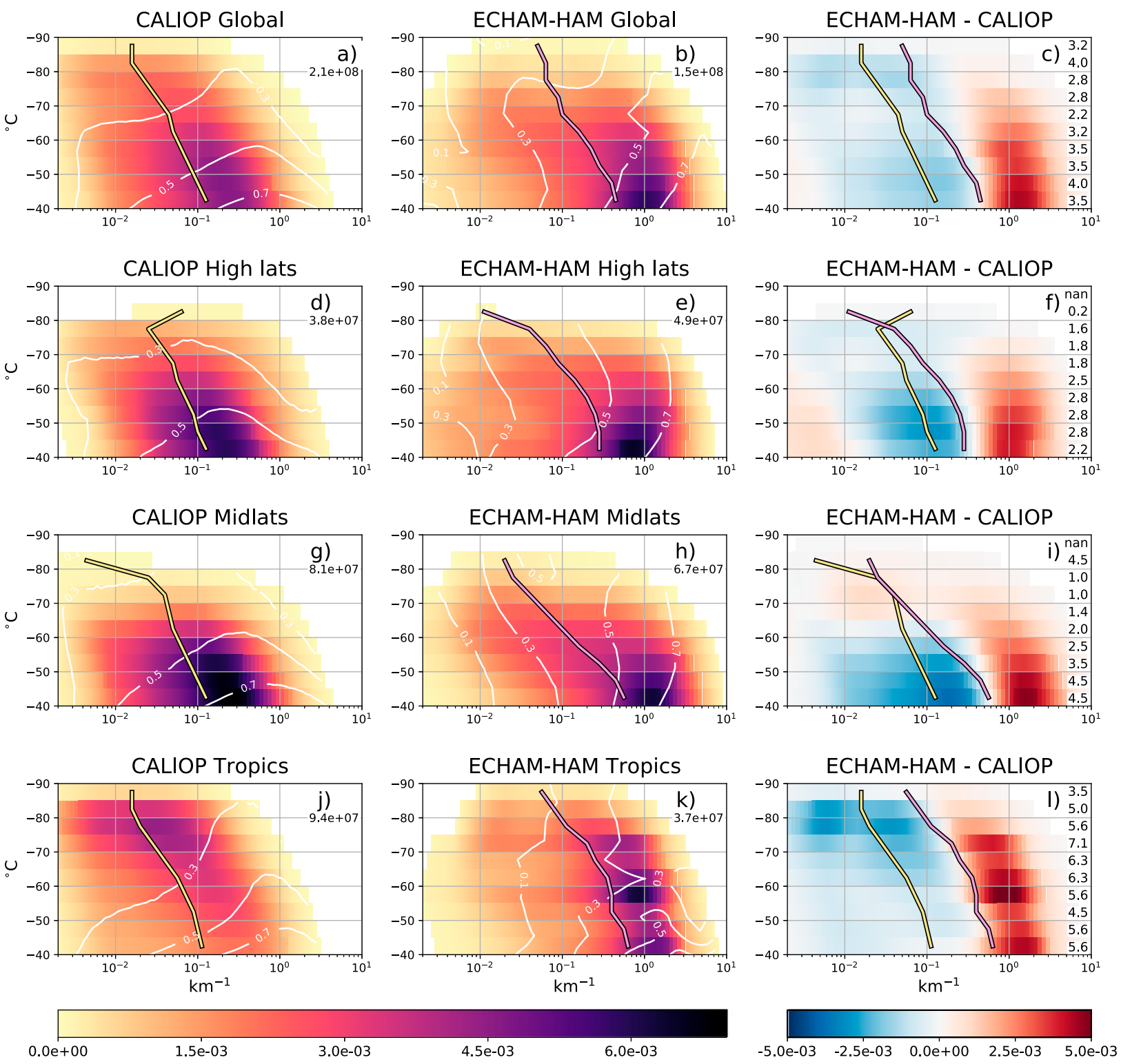

FIG. 3. Temperature-dependent frequency histograms of in-cloud extinction for (left) the CALIOP satellite and (center) the ECHAMHAM model for (top)-(bottom) global, high and middle latitudes, and the tropics. Numbers in the top-right corner of each panel represent the number of data points taken into account for specific plots. Yellow and plum lines represent the respective medians. White contour lines represent the fraction of liquid-origin EXT values. (right) Normalized difference between the two frequency distributions. Numbers on the right represent the value of the model median divided by the satellite median for each of the 10 temperature bins.

et al. 2010). Interestingly, the model simulates a larger amount of cirrus at warmer temperatures and less cirrus at colder temperatures (Table 1), which indicates a toolow convective detrainment level.

\section{2) ICE WATER CONTENT}

The globally averaged annual IWC distribution from Fig. 4a shows IWC values spanning over several orders of magnitude, with the temperature-dependent median values between $2 \times 10^{-4}$ and $8 \times 10^{-3} \mathrm{~g} \mathrm{~m}^{-3}$. These are reproduced remarkably well by the model (Figs. 4b,c), as the two median lines only rarely disagree for more than about $30 \%$.

We additionally compare our results with the global airborne IWC distribution of Schiller et al. (2008), who derived IWC from a fluorescence hygrometer on 52 
TABLE 1. Relative fraction of (EXT measurements)/model results that fall into the specified temperature range for CALIOP lidar and ECHAM-HAM model (parentheses).

\begin{tabular}{cccc}
\hline \hline Temp range $\left({ }^{\circ} \mathrm{C}\right)$ & Tropics $(\%)$ & Midlatitudes $(\%)$ & High latitudes $(\%)$ \\
\hline-90 to -80 & $13(6)$ & $0(1)$ & $0(0)$ \\
-70 to -80 & $28(21)$ & $3(8)$ & $12(8)$ \\
-60 to -70 & $23(23)$ & $18(23)$ & $22(23)$ \\
-50 to -60 & $20(27)$ & $36(33)$ & $31(31)$ \\
-40 to -50 & $16(23)$ & $43(35)$ & $35(38)$ \\
\hline
\end{tabular}

flights. The flights measured 3.5-h in-cloud cirrus data in the Arctic, $10.6 \mathrm{~h}$ in the midlatitudes, and $13 \mathrm{~h}$ in the tropics. Both CALIOP and ECHAM-HAM show higher IWCs than the in situ data, but the CALIOP and ECHAM-HAM median values agree within $20 \%-40 \%$ of the airborne observations, particularly for the temperatures warmer than $-75^{\circ} \mathrm{C}$. The values diverge more for the coldest clouds, which are often optically too thin to be detected by the CALIOP lidar (Heymsfield et al. 2017b) and the model, as we use the CALIOP detection limits. The median IWC decreases with temperature in all three datasets as a result of the decrease in the saturation vapor pressure at colder temperatures.

A regional analysis again reveals distinct cirrus cloud properties for the tropics compared to the mid- and high latitudes as shown in Fig. 4. In the tropics, cirrus clouds span over a large range of IWC, with the median ranging from $5 \times 10^{-2} \mathrm{~g} \mathrm{~m}^{-3}$ for temperatures warmer than $-55^{\circ} \mathrm{C}$ to $2 \times 10^{-4} \mathrm{~g} \mathrm{~m}^{-3}$ at the tropical tropopause, as observed by CALIOP.

The high IWC frequency band extending from $-40^{\circ}$ to $-70^{\circ} \mathrm{C}$ is likely caused by detrained ICs from tropical convective clouds (Jensen et al. 2017). The tropical tropopause cirrus clouds contain a median IWC of about $10^{-4} \mathrm{~g} \mathrm{~m}^{-3}$ in both the CALIOP observations and the model output. The model simulates an IWC frequency peak at the warmest temperature bins in the tropics (Fig. 4k), while the frequency of IWC-containing grid boxes is significantly smaller at the coldest temperatures, as suggested by Table 1 .

Extratropical cirrus clouds have a high IWC frequency peak at the warmest temperatures (approximately $-40^{\circ} \mathrm{C}$ ), ranging between $3 \times 10^{-3}$ and $2 \times 10^{-2} \mathrm{~g} \mathrm{~m}^{-3}$ for both the CALIOP satellite data and the model (Figs. 4d, $\mathrm{g}, \mathrm{e}, \mathrm{h})$. The CALIOP IWC peak in the extratropics is elongated toward smaller IWC values $\left(10^{-4} \mathrm{~g} \mathrm{~m}^{-3}\right)$ at temperatures between $-60^{\circ}$ and $-80^{\circ} \mathrm{C}$.

Interestingly, the IWC in the warmest cirrus clouds in Figs. 2g-i shows, unlike the medians in Fig. 4, a negative modeled IWC bias. Part of the apparent disagreement between the two figures is due to differences in the skewness of the IWC distribution as shown in Fig. S3 of the supplemental information. The modeled distribution is in general narrower and lacks a high value tail, probably associated with the largest precipitating ICs, which are excluded from the model analysis. These high values strongly influence the mean, while they only minimally affect the median of the distribution. The disagreement is particularly pronounced in the tropics. Additionally, we note a substantial disagreement between the in-cloud temperatures from CALIOP ancillary data and the model, with the model being up to $10^{\circ} \mathrm{C}$ colder in the lower range of cirrus cloud cover (Fig. S1a). The ancillary MERRA-2 temperatures have only a 6-hourly time step, which is longer than the lifetime of a typical cirrus cloud and therefore less representative for in-cloud temperatures as the ECHAM-HAM temperatures. ECHAM-HAM does, on the other hand, simulate well the all-sky temperatures compared with all-sky MERRA-2 data (Fig. S1b). Alternatively, ECHAM-HAM's EXT bias might prevent the retrieval of some of the lower-lying clouds with the highest IWC values as a result of the used column COD limit (Nam and Quaas 2012).

The simulated EXT is overestimated (Fig. 3), while the model and satellite agree well on the median IWC values (Fig. 4). This implies that the modeled cirrus clouds are optically too thick, which we attribute to an underestimation of IC particle size and/or overestimation of ice crystal number concentration (ICNC). To prove our hypothesis we performed an idealized sensitivity test in which we used the Heymsfield et al. (2014) temperature-dependent parameterization for IC radii, in the radiative part of the code, at temperatures warmer than $-65^{\circ} \mathrm{C}$, where the disagreement between the model and the parameterization is the largest (Figs. 2g,h). We kept the IWC and IC radii unchanged in the microphysical part of the model's code in order to approximately keep the same amount of IWC in the atmosphere. The sensitivity test more than halved the EXT disagreement (Fig. S4h in the supplemental information), proving that most of the discrepancy originated from the IC radii mismatch.

Since the IC radii used to derive the IWC from EXT are very uncertain, we performed another sensitivity test in which we derived the new CALIOP IWC by replacing the Heymsfield et al. (2014) formula with a 


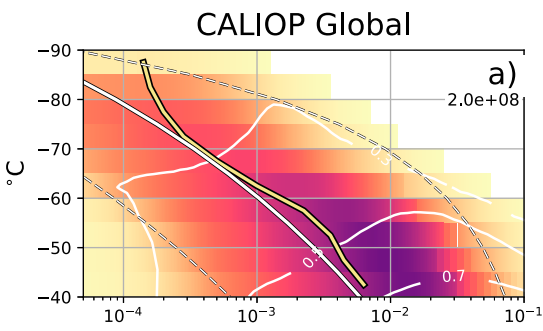

Ice water content
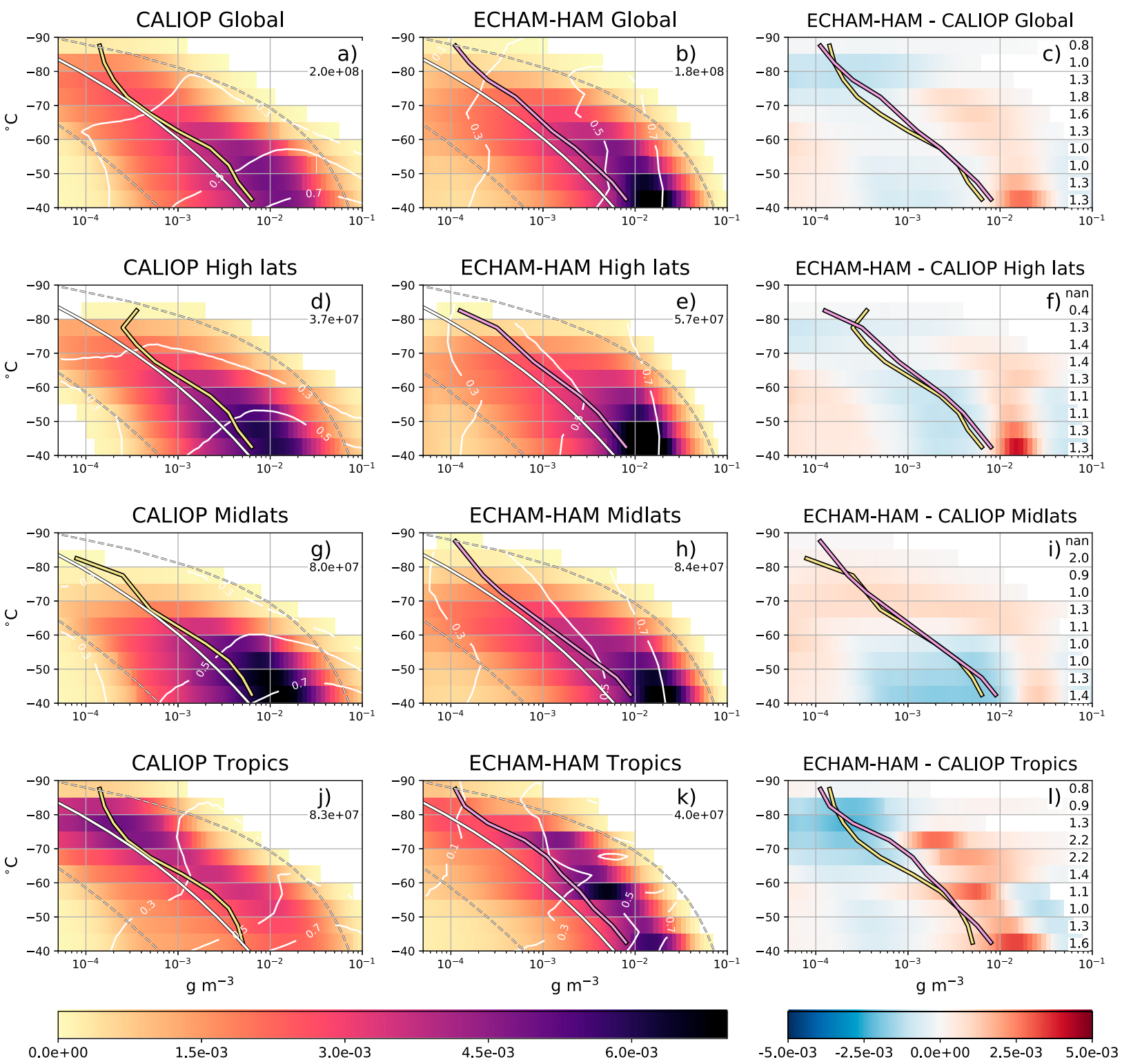

FIG. 4. As in Fig. 3 but for IWC. Shown are the median IWC values from Schiller et al. (2008; thick white lines) and their most frequent IWC range (dashed white lines).

linear interpolation of the median ECHAM-HAM IC radius (Fig. S2) in Eq. (1) (Fig. S5 in the supplemental information). Using the model-derived radius decreases the CALIOP-derived IWC by a factor of $2-3$ at temperatures between $-60^{\circ}$ and $-40^{\circ} \mathrm{C}$, consequently leading to a larger disagreement with the modeled IWC. The opposite happens in the coldest considered temperatures, where the IWC increases as a result of the larger modeled IC radius. We can consider the newly derived IWC as the lower bound of the CALIOP-derived IWC, as the model is likely underestimating the radius of ICs detrained from the convective outflow, which are particularly dominant in the tropics between $-40^{\circ}$ and $-60^{\circ} \mathrm{C}$.

\section{Origin of cirrus clouds}

a. In situ versus liquid origin

\section{1) Cloud Classification CRITERION}

We followed the classification by Luebke et al. (2016) and distinguished cirrus clouds both from the satellite and model data by those formed in an ice-only environment 
with in situ ice nucleation to those formed at warmer temperatures in the presence of liquid water. Unlike Luebke et al. (2016) or Wernli et al. (2016), we use the temperature limit of $-35^{\circ} \mathrm{C}$ instead of $-38^{\circ} \mathrm{C}$ for consistency with the homogeneous freezing temperature in ECHAM-HAM model. The different temperature criteria should not significantly influence the results, as there is only a minimal fraction of supercooled liquid present in the atmosphere at temperatures between $-38^{\circ} \mathrm{C}$ and $-35^{\circ} \mathrm{C}$ (Komurcu et al. 2014).

In this section, we used a simple criterion that gives a qualitative idea about the cirrus cloud formation mechanisms, but it cannot provide a precise quantitative analysis of the formation mechanisms. Nevertheless, the analysis helped us to better understand the cirrus cloud EXT and IWC distributions in Figs. 3, 4. The vertical profiles of the CALIOP lidar give instantaneous information about the state of cirrus clouds at a given point in time, without the details of its development. We scanned through CALIPSO lidar profiles in the search of cirrus clouds (at $T<-40^{\circ} \mathrm{C}$, IWC $>0.05 \mathrm{mg} \mathrm{m}^{-3}$, and COD $<3$ ) with cloud bases extending to $T>-35^{\circ} \mathrm{C}$ as depicted in Fig. 5. Such clouds were classified as liquid origin, with all the remaining clouds being tagged as in situ origin. The criterion is based on the assumption of a prevalent upward motion of air inside of a cloud, neglecting precipitating virga extending to temperatures warmer than $-35^{\circ} \mathrm{C}$. Additionally, we classify clouds that fulfill our cirrus cloud criterion and occur directly above fully attenuated lidar beams as liquid origin. Since the criterion is considering only vertical profiles without a horizontal dimension, it will inevitably miss some aged detrained (anvil) cirrus (Protopapadaki et al. 2017) or, similarly, cirrus in the slantwise ascending air associated with warm sectors of extratropical cyclones. Such cirrus clouds will be therefore erroneously classified as in situ formed (Fig. 5).

The cloud criterion applied to EXT and IWC distributions shows a distinct difference between the two cloud formation mechanisms: in situ cirrus dominates the colder temperatures at smaller EXT and IWC compared to the liquid-origin ones. Liquid-origin cirrus contain on average twice the amount of IWC as in situ cirrus and are by about the same factor optically thicker, as shown in both the CALIOP and ECHAM-HAM datasets (Fig. 6).

More than $50 \%$ of the cirrus clouds in the range between $-40^{\circ}$ and $-55^{\circ} \mathrm{C}$ have a liquid origin, with the number quickly decreasing to about $20 \%$ between $-75^{\circ}$ and $-90^{\circ} \mathrm{C}$. The global average fraction of liquid-origin clouds of $45 \%-50 \%$ agrees well between the CALIOP and ECHAM-HAM data. The pattern of the fraction of liquid-origin cirrus in Fig. 6 differs between the model

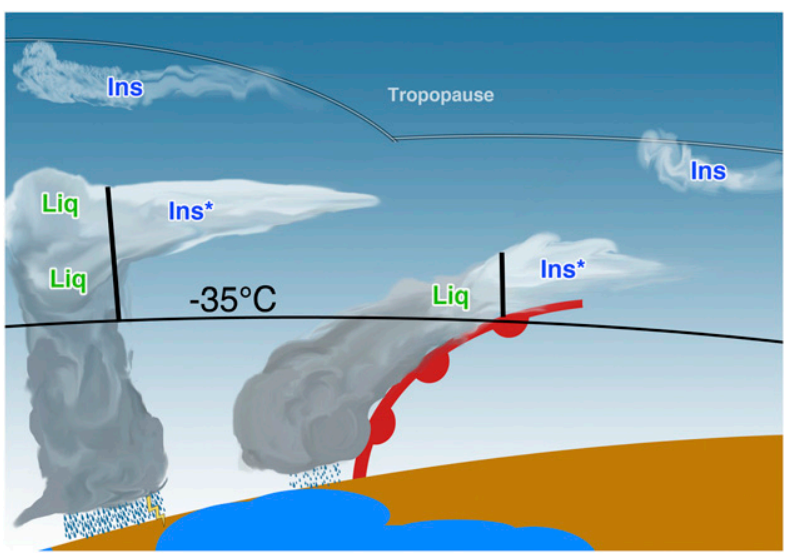

FIG. 5. Sketch of the cirrus cloud classification algorithm. The Liq refers to liquid-origin cirrus, Ins to in situ cirrus, and Ins* are liquid-origin cirrus that are erroneously classified by our algorithm as in situ.

and CALIOP because the highest EXT and IWC data points are affected by the limitations of the lidar measurements. Therefore, we also distinguish between the liquid-origin and in situ cirrus in two years (2008-09) of the combined CALIOP lidar and CloudSat radar product (DARDAR; Delanoe and Hogan 2010), which avoids the lidar beam attenuation problem. DARDAR's liquid-origin cloud fraction pattern looks more similar to the modeled one than the pattern from CALIOP data (Fig. S6 in the supplemental information). Moreover, DARDAR's total liquid-origin fraction is slightly higher compared to CALIOP, resulting from the absence of the attenuation problem and a higher minimum detection threshold. DARDAR also measures less of the thinnest, preferentially in situ origin cirrus.

Regionally, the fraction of liquid-origin clouds from both CALIOP and ECHAM-HAM peaks in midlatitudes with values close to $50 \%$, while it decreases to about $40 \%$ in high latitudes, which is not reproduced by the model. The liquid-origin pattern is similar in all three regions, peaking at high EXT-IWC values at the warmest considered temperatures (Figs. 3, 4). The relative importance of liquid-origin cirrus seems to agree well with the Lagrangian trajectory study by Wernli et al. (2016), while it shows a higher liquid-origin fraction compared to Gryspeerdt et al. (2017). We also note the possibility of a misclassification of in situ-nucleated ICs in air masses adjacent to a frontal ascent or a convective core as liquid origin as a result of the continuous, unbroken cloud layer, as shown in Figs. 4b,d in Wernli et al. (2016) for the case of an extratropical cyclone. Tropics, being dominated by detrainment from deep convective clouds, have a considerably smaller amount of liquid-origin cirrus ( $\sim 20 \%$ for CALIOP and $\sim 30 \%$ 

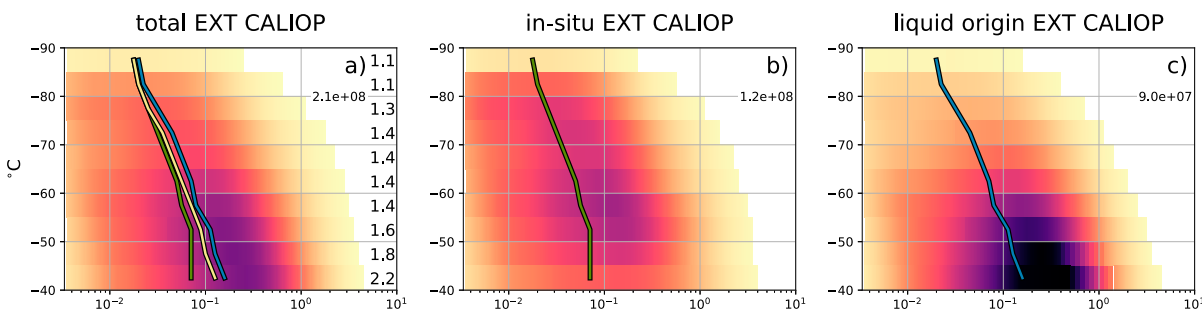

$\%$ of liquid origin EXT CALIOP
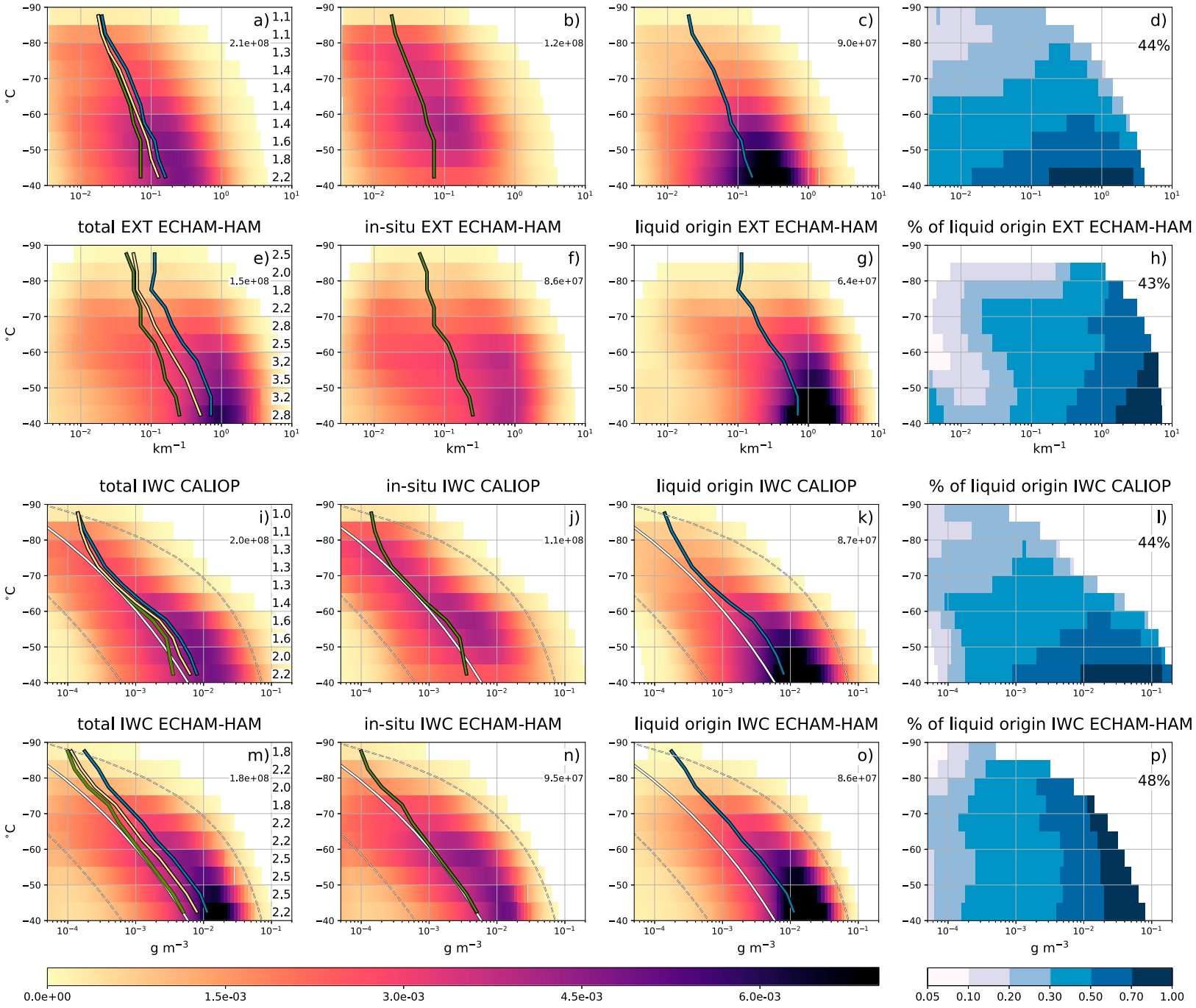

$3.0 \mathrm{e}-03$

$$
4.5 \mathrm{e}-03
$$$$
6.0 \mathrm{e}-03
$$

$\%$ of liquid origin IWC ECHAM-HAM

FIG. 6. Temperature-dependent frequency histograms of (a) total EXT, (b) in situ EXT, (c) liquid-origin EXT, and (d) percent of liquidorigin EXT for the CALIOP satellite and (e)-(h) for the ECHAM-HAM model. (i)-(p) As in (a)-(h), but for IWC. Number in the topright corner of each panel (except the last column) represents the number of data points taken into account for specific plots. Colored lines in each of the panels (except the last column) represent the full dataset (yellow), in situ (green), and liquid-origin (blue) median values. Numbers on the right of the (left) represent the value of the liquid-origin median divided by the in situ median for each of the 10 temperature bins. Continuous white lines in the lower half of the figure represent the median IWC from Schiller et al. (2008), where the dashed white lines encompass their most frequent IWC range. (right) Ratio between the (middle right) liquid-origin data and the (left) full dataset values. Percentage refers to the total fraction of liquid-origin EXT and IWC.

for ECHAM-HAM) compared to studies using trajectories (Luo and Rossow 2004; Riihimaki et al. 2012), exposing the limitations of our criterion.

\section{2) Model SEnsitivity TESTS}

We additionally performed ECHAM-HAM simulations in which we turned off either the liquid-origin cirrus (simulation NOLIQ), the homogeneous ice nucleation (HET), or the heterogeneous ice nucleation (HOM). We note that while the following model results are interesting, they currently cannot be verified by remote sensing observations and should therefore be interpreted with caution.

We start by describing the model simulation in which cirrus can form only by in situ ice nucleation (NOLIQ). We did that by suppressing the convective outflow of ICs at $T<-40^{\circ} \mathrm{C}$, not allowing any cloud droplet to freeze. In addition, the ICs from mixed-phase clouds were not allowed to be transported to the cirrus regime. Figure 7 shows the globally averaged difference between the 

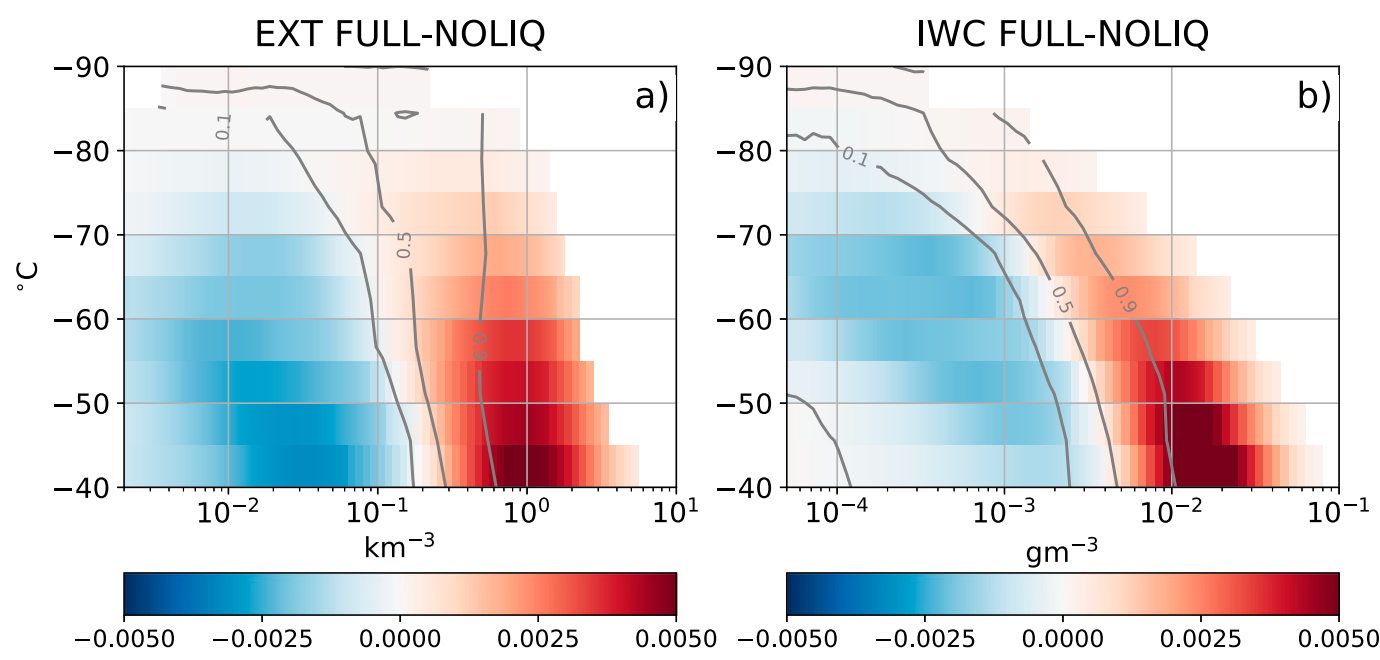

FIG. 7. Global frequency anomaly histograms from ECHAM-HAM sensitivity tests. Plotted is the anomaly between the reference (FULL) and NOLIQ simulation for (a) EXT and (b) IWC. A positive anomaly indicates areas of preferential liquid-origin cirrus clouds, while a negative anomaly indicates areas where in situ-formed clouds dominate. Gray contour lines represent the relative fraction of liquid-origin clouds computed as (FULLNOLIQ)/FULL, providing results comparable to Figs. 6d,h,l,p.

reference simulation (FULL) and NOLIQ for EXT and IWC.

The shift toward higher EXT and IWC in Figs. 7a,b shows that liquid-origin clouds contain several times larger EXT and IWC compared to in situ ones, confirming the results from aircraft data by Luebke et al. (2016) and Krämer et al. (2016). The anomalies are most pronounced in the temperature range between $-60^{\circ}$ and $-40^{\circ} \mathrm{C}$, which is consistent with Voigt et al. (2017), who showed that liquid-origin cirrus dominate in the $\mathrm{NH}$ midlatitudes at temperatures warmer than $-55^{\circ} \mathrm{C}$. This sensitivity test reinforces the interpretation of the model-derived cirrus cloud properties in Fig. 6 and the usefulness of our simple cloud classification criterion. The difference between FULL and NOLIQ is consistent throughout all of the considered regions, including the tropics, and therefore exposes the problem of the misclassification of aged anvils mentioned in the previous subsection.

Figure 8 shows the globally averaged modeled ICNC versus the IC effective radii to reveal additional information about the IC formation mechanisms (see subsection $4 \mathrm{c}$ ). The plots show that liquid-origin cirrus form mainly by convection with up to $10^{4}$ ICs per liter, which grow by deposition of water vapor to sizes of $\sim 50 \mu \mathrm{m}$. Moreover, the ICs are transferred to snow by aggregation, resulting in a rapid decrease of their number concentration. On the other hand, in situ ICs primarily have number concentrations below $30 \mathrm{~L}^{-1}$, which is consistent with in situ data from Krämer et al. (2016) and Luebke et al. (2016). Our in situ-formed ICs span over a large size range, while the liquid-origin ICs are often smaller. Unlike that speculated in the referenced two studies, most of our liquid-origin cirrus are formed by homogeneous nucleation of cloud droplets in convective updrafts and not by heterogeneous ice nucleation in the mixed-phase environment.

\section{b. Homogeneous versus heterogeneous ice crystal formation model sensitivity test}

In addition, simulations HOM and HET allow us to better understand the size and number concentration of IC originating from the two in situ freezing mechanisms. Similar to Fig. 8c, Fig. 9 relates the anomalies of ICNC to IC effective radius occurrence frequency. Meanwhile, Fig. S7 in the supplemental information shows the frequencies of each of the two simulations separately.

The in situ ice nucleation mechanisms on average play a minor role compared with the liquid versus in situ origin comparison, when displayed in the ICNC (IC radius) phase space. Heterogeneous nucleation clearly dominates for IC radii between 5 and $20 \mu \mathrm{m}$ with an ICNC of $1-30 \mathrm{~L}^{-1}$ as shown by the positive anomalies in Fig. 9a. Such ICs form prevalently at the coldest temperatures of the upper troposphere, where the vapor availability is not large enough to allow the growth of large ICs. The frequency increase at IC radii between 20 and $70 \mu \mathrm{m}$ is not as clearly visible because of the homogeneous and liquid-origin ICs, which are also frequent in that IC size range (Fig. 9a). In addition, heterogeneous ICs suppress numerous homogeneous nucleation events, substantially decreasing the total 
FULL

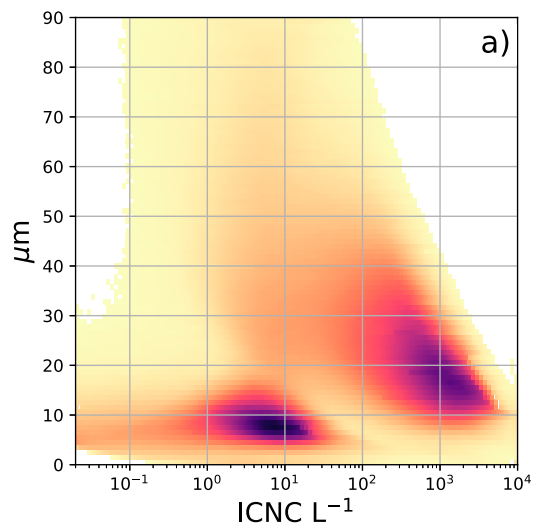

Global ICNC (IC radius) NOLIQ

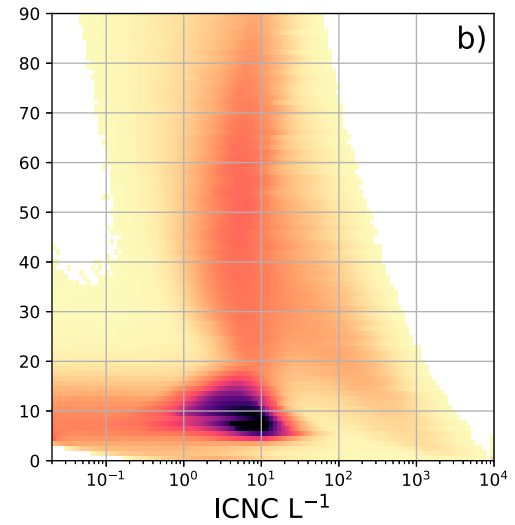

FULL-NOLIQ

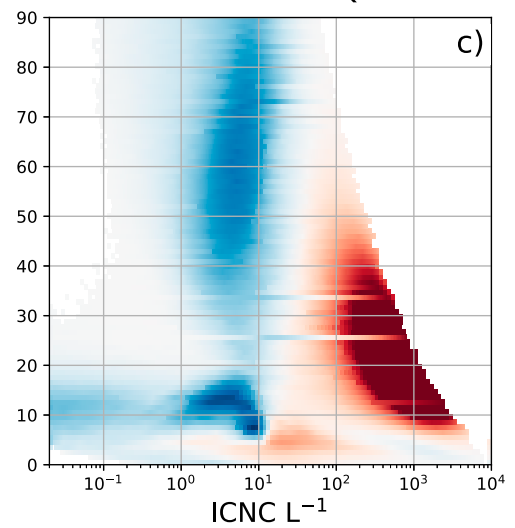

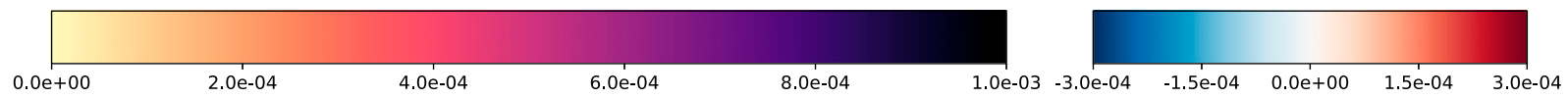

FIG. 8. Global frequency histogram of ICNC as a function of IC effective radii from ECHAM-HAM sensitivity tests. Occurrence frequencies for the (a) FULL and (b) NOLIQ simulations. (c) Normalized frequency differences between the FULL and NOLIQ simulations.

ICNC. On the other hand, the most pronounced positive anomalies in Fig. 9b expose the preferential locations of homogeneously formed ICs. Homogeneous nucleation results in ICNCs between about 20 and $2000 \mathrm{~L}^{-1}$ and an
IC radius between 5 and $25 \mu \mathrm{m}$, which can further grow by deposition to sizes of up to $50 \mu \mathrm{m}$ (Fig. 9b). We note that the sensitivity of the cirrus nucleation scheme to heterogeneous freezing is, at this stage, still largely

\section{Global ICNC (IC radius)}
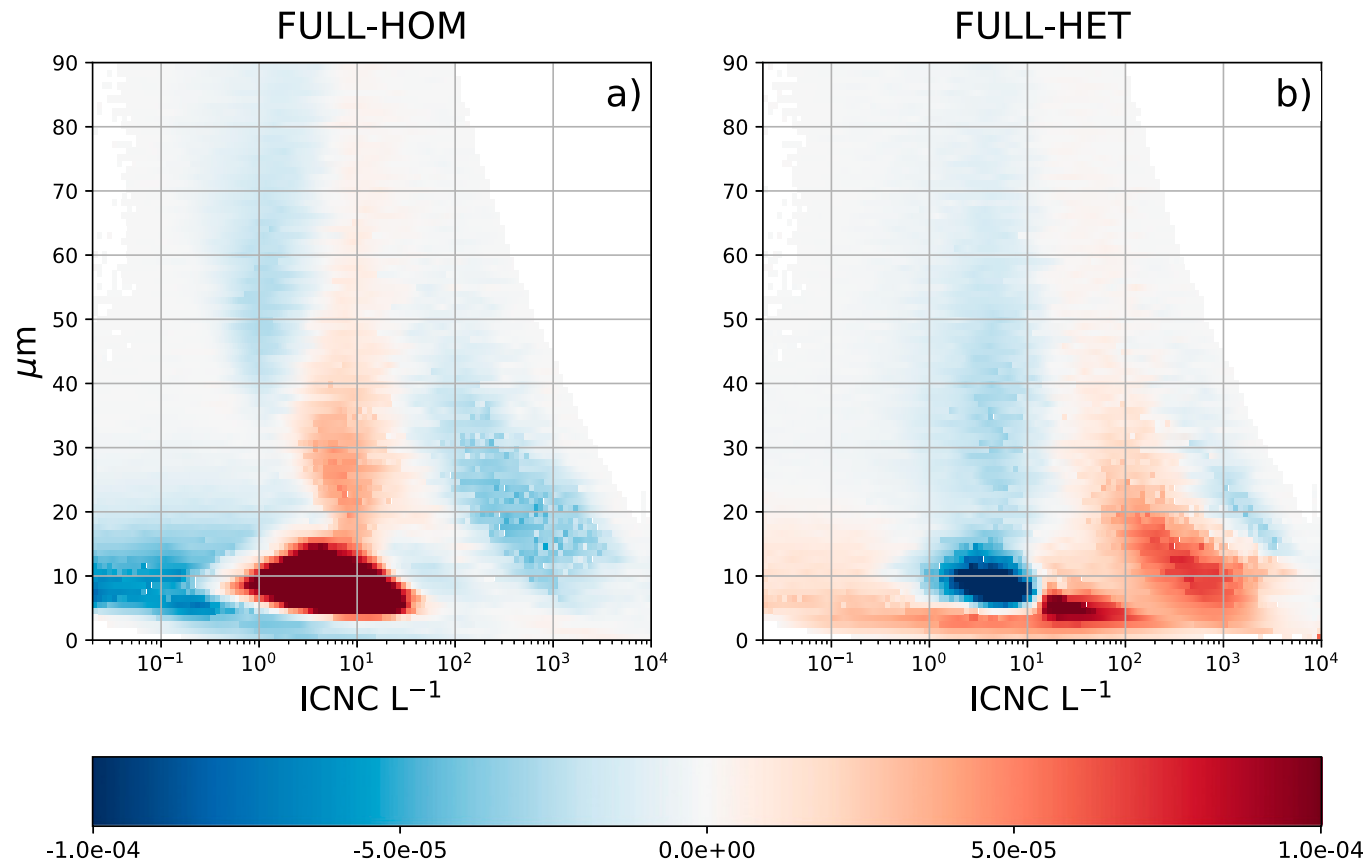

FIG. 9. Global frequency histogram of ICNC as a function of IC effective radii from ECHAM-HAM sensitivity tests. (a) Normalized frequency differences between the FULL and HOM simulations, where positive anomalies indicate a preference for heterogeneous ice nucleation. (b) As in (a), but for FULL - HET simulations, where the positive anomalies indicate a preference for homogeneous ice nucleation. 
model dependent and can vary significantly based on the inclusion of preexisting ice (Kuebbeler et al. 2014; Shi et al. 2015), a background INP concentration (Zhou and Penner 2014), and the deep- and midlevel convective tuning parameters (Gasparini 2016). Moreover, a positive cloud cover bias over mountains (Fig. 1c), which are dominated by homogeneously formed ICs, suggests a possible model overestimation of homogeneous nucleation.

\section{c. Ice crystal formation sources}

As a summary, we try to reconcile the IC sources and growth mechanisms in a sketch in Fig. 10, which relates the ICNC as a function of IC effective radius. The plotted area can be distinguished in three clusters representing the three IC nucleation pathways:

- Detrained (liquid origin) ICs typically form at ICNCs of $10^{2}-10^{4} \mathrm{~L}^{-1}$ with IC radii of $10-20 \mu \mathrm{m}$. The majority of ICs are formed and then quickly transferred to snow by IC aggregation, while the remaining ICs grow by vapor deposition to sizes near $50 \mu \mathrm{m}$. Detrained IC are dominant at temperatures between $-40^{\circ}$ and $-55^{\circ} \mathrm{C}$ (Fig. 7), extending to colder temperatures in the tropics.

- Homogeneously formed ICs show similar properties and are therefore hard to separate from the detrained IC signal. However, their growth by deposition is less efficient, as they form mainly at colder temperatures (colder than $-55^{\circ} \mathrm{C}$ ) and therefore rarely exceed sizes of $20 \mu \mathrm{m}$ (Fig. 9b).

- Heterogeneously formed ICs dominate at number concentrations between about 0.5 and $20 \mathrm{~L}^{-1}$ and sizes between 5 and $60 \mu \mathrm{m}$, for IWC values close to or just below the CALIOP lidar detection limit. Many form at low temperatures and low supersaturations, where the vapor availability is low, limiting IC growth by deposition. Nevertheless, the sizes of freshly nucleated heterogeneous ICs directly after the cirrus nucleation module are larger than those formed by homogeneous freezing (Kuebbeler et al. 2014). In addition, heterogeneous nucleation events occur frequently in the area where aged, larger, detrained, and homogeneously nucleated ICs dominate as a result of their significantly larger number concentrations, masking the heterogeneous IC signal in the Fig. 10. Therefore, the ICNC (IC radius) phase space is probably not the best metric for determining the importance of heterogeneous nucleation on climate.

In summary, distinguishing between in situ and liquidorigin IC formation mechanisms is not straightforward, as the model does not keep track of several IC modes after their nucleation and initial growth by vapor deposition (Kuebbeler et al. 2014). Additional microphysical processes, like further depositional growth, IC

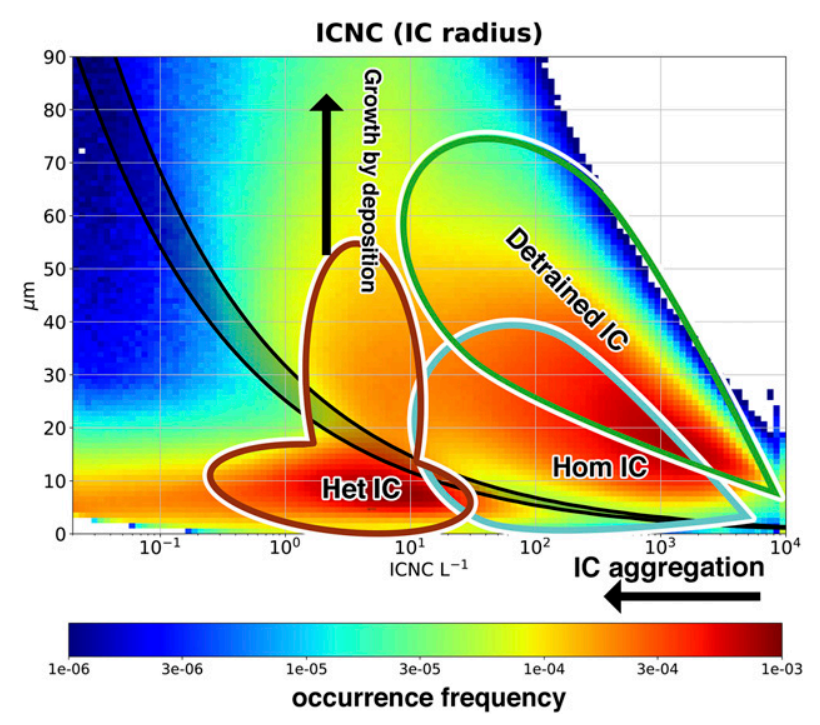

FIG. 10. Global frequency histogram of ICNC as a function of IC effective radii from ECHAM-HAM. Preferential properties of IC formation mechanisms are encircled. ICs grow by deposition by moving vertically toward larger sizes, and they are frequently removed by aggregation to form snowflakes, decreasing their ICNC, exhibiting a horizontal shift. Approximate IWC region of the CALIOP nighttime detection limit $\left(0.05-0.1 \mathrm{mg} \mathrm{m}^{-3}\right.$; gray-shaded area between the two black lines). The labels het, hom, and detrained ICs refer to areas where the heterogeneous, homogeneous, and detrained ICs, respectively, are dominant.

loss by sedimentation, and aggregation, can significantly modify IC properties after they are nucleated, smearing out signals of their nucleation pathways.

\section{Conclusions}

We studied nighttime cirrus cloud properties in the ECHAM-HAM GCM and compared them with CALIOP satellite data. The modeled cirrus cloud cover follows the observed cirrus distribution from the CALIPSO-ST and CALIPSO-GOCCP satellite products with peaks in the tropics, and secondary peaks over the storm-track regions. The largest model bias is the underestimation of the tropical cirrus by about $10 \%-$ $25 \%$ and the lack of a clear ITCZ signal in terms of both cloud cover and IWP. There are also indications of an overestimation of detrainment from deep convective clouds at low altitudes in the tropics in ECHAM-HAM compared to CALIOP. Consequently, the results point at a too-low convective detrainment level (Table 1) despite a large decrease in the deep convective entrainment tuning parameter compared to the standard ECHAM-HAM model version. In addition, the cloud cover is overestimated in the extratropical tropopause region as a result of positive relative humidity and 
negative temperature bias. This bias cannot be solved by changes in the microphysical parameterizations alone, as it is likely connected to the models' resolution (Stevens et al. 2013). The model also overestimates cirrus occurrence over mountains in the extratropics, caused by a combination of the increased vertical velocities by the orographic cirrus scheme and the extratropical relative humidity bias.

ECHAM-HAM simulates about $30 \%$ lower IWP in the global annual mean compared to CALIOP data (Figs. 1g-i). Most of the bias originates from the lowest considered altitude levels (Figs. 2g-i) where the model fails to simulate the upper tail of the IWC distribution, as the largest ICs are precipitated out of the atmosphere and are thus excluded from this analysis. On the other hand, the median IWC in the temperature-dependent IWC histogram (Figs. 4a-c) shows that the model overestimates the IWC by up to $30 \%$. This is caused by the small sensitivity of the distribution median to the highest IWC values, and a large temperature disagreement between the in-cloud CALIOP ancillary temperature data and the simulated temperature field.

The IWC is a highly derived satellite product that relies on the Heymsfield et al. (2014) parameterization uncertainties. As shown by Heymsfield et al. (2017a), their IWC dataset is mainly populated with high tropical IWC measurements and is therefore probably overestimating the IWC in the extratropics. The temperature-dependent distribution of EXT is overestimated by the model by a factor of 2-4 (Figs. 3a-c), while it simulates remarkably similar median IWC values. The model sensitivity test proved that the largest part of this bias can be attributed to the disagreement between the IC radius size used in the CALIOP dataset to derive the IWC fields and the modeled IC radii. ECHAM-HAM simulates smaller IC radii in the temperature range between $-40^{\circ}$ and $-65^{\circ} \mathrm{C}$, which leads to optically thicker clouds with higher EXT. Moreover, considering the large observational uncertainties on IC radii, future work should try to improve the cirrus scheme to better reproduce the more reliable EXT from CALIOP data.

The distributions of EXT, IWC, ICNC, and IC effective radii from both CALIOP and ECHAM-HAM data point at two separate types of cirrus clouds.

- In situ-formed clouds prevail at temperatures colder than $-55^{\circ} \mathrm{C}$. Their low IWC (below $\sim 1 \mu \mathrm{g} \mathrm{m}^{-3}$ ) translates into typical EXT values between $10^{-3}$ and $10^{-1} \mathrm{~km}^{-1}$ at $532-\mathrm{nm}$ wavelength.

- Liquid-origin cirrus form in the liquid or mixed phase and subsequently freeze at temperatures colder than $-40^{\circ} \mathrm{C}$ or freeze in the mixed-phase regime and are transported to cirrus conditions. They are associated with large IWC, EXT, and ICNC of 100-10000 ICs per liter.

We performed model sensitivity tests to separate the signals of homogeneously and heterogeneously nucleated ICs. First, we note that the anomalies between simulations in which we either turned off homogeneous or heterogeneous in situ freezing and the full cirrus scheme are smaller compared with an analogous liquid versus in situ origin comparison. This indicates that the details of in situ ice formation play a minor role compared with liquid-origin cirrus in our model. We found that homogeneously formed ICs can generally be found at ICNC between 20 and $2000 \mathrm{~L}^{-1}$, while heterogeneous ICs prevail at ICNCs lower than $30 \mathrm{~L}^{-1}$. However, the heterogeneous signal is partially smeared out by an increased contribution of a larger number concentration of ICs from homogeneous and detrained sources. We find a clear heterogeneous signal only from freshly nucleated small ICs, likely formed close to the tropopause at the coldest considered temperatures and small supersaturations with respect to ice.

The annually averaged cirrus cloud properties differ significantly between the tropics and extratropics. This is due to the large importance of deep convective outflow and a larger temperature range for cirrus formation in the tropics, as well as the attenuation of the lidar beam. This is particularly true for the CALIOP data, while the simulated cirrus shows the same temperaturedependent EXT and IWC trends at all latitudinal bands.

In conclusion, the availability of new satellite products from CloudSat and CALIPSO have greatly reduced the range of uncertainties in cirrus cloud properties at the global scale, providing critical information for the climate modeling community. However, the current satellite data cannot give precise information about cirrus formation mechanisms. As the ice phase and in particular IC formation mechanisms still remain highly uncertain, we call for more comprehensive studies of ice nucleation pathways, because of their implications on the global energy budget and cirrus cloud geoengineering (Lohmann and Gasparini 2017).

Acknowledgments. Angela Meyer and Blaž Gasparini contributed equally to this work.

The CALIPSO data were provided by the Atmospheric Science Data Center of the NASA Langley Research Center (https://eosweb.larc.nasa.gov). The simulations were performed on the Daint cluster of the Swiss Supercomputing Center (Project s431) and on the Euler ETHZ computational cluster. D. Neubauer gratefully acknowledges the financial support provided by the Swiss National Science Foundation (SNSF, Project 
200021-160177). S. Münch was supported by the Swiss National Science Foundation under Project 200021E166726. We thank Mark Vaughan and Melody Avery of the CALIPSO science team at the NASA Langley Research Center for the constructive discussions. We thank Robert David and the anonymous reviewers for their suggestions, which improved the manuscript; and Marina Dütsch for her help with Python scripting. The data from the model simulations are available from the authors upon request.

\section{REFERENCES}

Avery, M., D. Winker, A. Heymsfield, M. Vaughan, S. Young, Y. Hu, and C. Trepte, 2012: Cloud ice water content retrieved from the CALIOP space-based lidar. Geophys. Res. Lett., 39, L05808, https://doi.org/10.1029/2011GL050545.

Barahona, D., A. Molod, and H. Kalesse, 2017: Direct estimation of the global distribution of vertical velocity within cirrus clouds. Sci. Rep., 7, 6840, https://doi.org/10.1038/ s41598-017-07038-6.

Berry, E., and G. G. Mace, 2014: Cloud properties and radiative effects of the Asian summer monsoon derived from A-Train data. J. Geophys. Res. Atmos., 119, 9492-9508, https://doi.org/ 10.1002/2014JD021458.

Bodas-Salcedo, A., and Coauthors, 2011: COSP: Satellite simulation software for model assessment. Bull. Amer. Meteor. Soc., 92, 1023-1043, https://doi.org/10.1175/2011BAMS2856.1.

Boudala, F. S., G. A. Isaac, Q. Fu, and S. G. Cober, 2002: Parameterization of effective ice particle size for high-latitude clouds. Int. J. Climatol., 22, 1267-1284, https://doi.org/10.1002/ joc. 774 .

Cesana, G., and H. Chepfer, 2012: How well do climate models simulate cloud vertical structure? A comparison between CALIPSO-GOCCP satellite observations and CMIP5 models. Geophys. Res. Lett., 39, 20803, https://doi.org/10.1029/ 2012GL053153.

Chen, T., W. B. Rossow, and Y. Zhang, 2000: Radiative effects of cloud-type variations. J. Climate, 13, 264-286, https://doi.org/ 10.1175/1520-0442(2000)013<0264:REOCTV>2.0.CO;2.

Chepfer, H., S. Bony, D. Winker, G. Cesana, J. L. Dufresne, P. Minnis, C. J. Stubenrauch, and S. Zeng, 2010: The GCMOriented CALIPSO Cloud Product (CALIPSO-GOCCP). J. Geophys. Res., 115, D00H16, https://doi.org/10.1029/ 2009JD012251.

— D. Cesana, D. Winker, B. Getzewich, M. Vaughan, and Z. Liu, 2013: Comparison of two different cloud climatologies derived from CALIOP-attenuated backscattered measurements (level 1): The CALIPSO-ST and the CALIPSOGOCCP. J. Atmos. Oceanic Technol., 30, 725-744, https:// doi.org/10.1175/JTECH-D-12-00057.1.

Corti, T., and T. Peter, 2009: A simple model for cloud radiative forcing. Atmos. Chem. Phys., 9, 5751-5758, https://doi.org/ 10.5194/acp-9-5751-2009.

Cziczo, D. J., and Coauthors, 2013: Clarifying the dominant sources and mechanisms of cirrus cloud formation. Science, 340, 1320-1324, https://doi.org/10.1126/science.1234145.

Davis, S., and Coauthors, 2010: In situ and lidar observations of tropopause subvisible cirrus clouds during TC4. J. Geophys. Res., 115, D00J17, https://doi.org/10.1029/ 2009JD013093.
Delanoe, J., and R. J. Hogan, 2010: Combined CloudSatCALIPSO-MODIS retrievals of the properties of ice clouds. J. Geophys. Res., 115, D00H29, https://doi.org/10.1029/ 2009JD012346.

Dinh, T., A. Podglajen, A. Hertzog, B. Legras, and R. Plougonven, 2016: Effect of gravity wave temperature fluctuations on homogeneous ice nucleation in the tropical tropopause layer. Atmos. Chem. Phys., 16, 35-46, https://doi.org/10.5194/ acp-16-35-2016.

Field, P. R., and R. Wood, 2007: Precipitation and cloud structure in midlatitude cyclones. J. Climate, 20, 233-254, https:// doi.org/10.1175/JCLI3998.1.

Fusina, F., P. Spichtinger, and U. Lohmann, 2007: Impact of ice supersaturated regions and thin cirrus on radiation in the midlatitudes. J. Geophys. Res., 112, D24S14, https://doi.org/ 10.1029/2007JD008449.

Garnier, A., J. Pelon, M. A. Vaughan, D. M. Winker, C. R. Trepte, and P. Dubuisson, 2015: Lidar multiple scattering factors inferred from CALIPSO lidar and IIR retrievals of semi-transparent cirrus cloud optical depths over oceans. Atmos. Meas. Tech., 8, 2759-2774, https://doi.org/10.5194/ amt-8-2759-2015.

Gasparini, B., 2016: Cirrus clouds and their geoengineering potential. Ph.D. thesis, ETH Zürich, 168 pp., https://doi.org/ 10.3929/ethz-b-000000052.

— substantially cool the planet. J. Geophys. Res. Atmos., 121, 4877-4893, https://doi.org/10.1002/2015JD024666.

_, S. Münch, L. Poncet, M. Feldmann, and U. Lohmann, 2017: Is increasing ice crystal sedimentation velocity in geoengineering simulations a good proxy for cirrus cloud seeding? Atmos. Chem. Phys., 17, 4871-4885, https://doi.org/10.5194/ acp-17-4871-2017.

Gates, W. L., 1992: AMIP: The Atmospheric Model Intercomparison Project. Bull. Amer. Meteor. Soc., 73, 1962-1970, https://doi.org/ 10.1175/1520-0477(1992)073<1962:ATAMIP>2.0.CO;2.

Gryspeerdt, E., J. Quaas, T. Goren, D. Klocke, and M. Brueck, 2017: Technical note: An automated cirrus classification. Atmos. Chem. Phys. Discuss., https://doi.org/10.5194/ acp-2017-723.

Haladay, T., and G. Stephens, 2009: Characteristics of tropical thin cirrus clouds deduced from joint CloudSat and CALIPSO observations. J. Geophys. Res., 114, D00A25, https://doi.org/ 10.1029/2008JD010675.

Hartmann, D. L., J. R. Holton, and Q. Fu, 2001: The heat balance of the tropical tropopause, cirrus, and stratospheric dehydration. Geophys. Res. Lett., 28, 1969-1972, https://doi.org/ 10.1029/2000GL012833.

Herzegh, P. H., and P. Hobbs, 1980: The mesoscale and microscale structure and organization of clouds and precipitation in midlatitude cyclones. II: Warm-frontal clouds. J. Atmos. Sci., 37, 597-611, https://doi.org/10.1175/1520-0469(1980)037<0597: TMAMSA $>2.0 . \mathrm{CO} ; 2$.

Heymsfield, A. J., D. Winker, M. Avery, M. Vaughan, G. Diskin, M. Deng, V. Mitev, and R. Matthey, 2014: Relationships between ice water content and volume extinction coefficient from in situ observations for temperatures from $0^{\circ}$ to $-86^{\circ} \mathrm{C}$ : Implications for spaceborne lidar retrievals. J. Appl. Meteor. Climatol., 53, 479-505, https://doi.org/ 10.1175/JAMC-D-13-087.1.

—, M. Krämer, N. B. Wood, A. Gettelman, P. R. Field, and G. Liu, 2017a: Dependence of the ice water content and snowfall rate on temperature, globally: Comparison of in situ 
observations, satellite active remote sensing retrievals, and global climate model simulations. J. Appl. Meteor. Climatol., 56, 189-215, https://doi.org/10.1175/JAMC-D-16-0230.1.

—, and Coauthors, 2017b: Cirrus clouds. Ice Formation and Evolution in Clouds and Precipitation: Measurement and Modeling Challenges, Meteor. Monogr., No. 58, Amer. Meteor. Soc., 2.1-2.26, https://doi.org/10.1175/ AMSMONOGRAPHS-D-16-0010.1.

Hoose, C., and O. Möhler, 2012: Heterogeneous ice nucleation on atmospheric aerosols: A review of results from laboratory experiments. Atmos. Chem. Phys., 12, 9817-9854, https:// doi.org/10.5194/acp-12-9817-2012.

Ickes, L., A. Welti, C. Hoose, and U. Lohmann, 2015: Classical nucleation theory of homogeneous freezing of water: Thermodynamic and kinetic parameters. Phys. Chem. Chem. Phys., 17, 5514-5537, https://doi.org/10.1039/C4CP04184D.

Isotta, F. A., P. Spichtinger, U. Lohmann, and K. von Salzen, 2011: Improvement and implementation of a parameterization for shallow cumulus in the global climate model ECHAM5HAM. J. Atmos. Sci., 68, 515-532, https://doi.org/10.1175/ 2010JAS3447.1.

Jensen, E. J., and Coauthors, 2016: On the susceptibility of cold tropical cirrus to ice nuclei abundance. J. Atmos. Sci., 73, 24452464, https://doi.org/10.1175/JAS-D-15-0274.1.

- , and Coauthors, 2017: The NASA Airborne Tropical Tropopause Experiment: High-altitude aircraft measurements in the tropical western Pacific. Bull. Amer. Meteor. Soc., 98, 129-143, https://doi.org/10.1175/BAMS-D-14-00263.1.

Joos, H., P. Spichtinger, U. Lohmann, J. F. Gayet, and A. Minikin, 2008: Orographic cirrus in the global climate model ECHAM5. J. Geophys. Res., 113, D18205, https://doi.org/ 10.1029/2007JD009605.

,,-- P. Reutter, and F. Fusina, 2014: Influence of heterogeneous freezing on the microphysical and radiative properties of orographic cirrus clouds. Atmos. Chem. Phys., 14, 6835-6852, https://doi.org/10.5194/acp-14-6835-2014.

Kanji, Z. A., L. A. Ladino, H. Wex, Y. Boose, M. Burkert-Kohn, D. J. Cziczo, and M. Krämer, 2017: Overview of ice nucleating particles. Ice Formation and Evolution in Clouds and Precipitation: Measurement and Modeling Challenges, Meteor. Monogr., No. 58, Amer. Meteor. Soc., 1.1-1.33, https://doi.org/ 10.1175/AMSMONOGRAPHS-D-16-0006.1.

Kärcher, B., 2017: Cirrus clouds and their response to anthropogenic activities. Curr. Climate Change Rep., 3, 45-57, https:// doi.org/10.1007/s40641-017-0060-3.

_ _ J. Hendricks, and U. Lohmann, 2006: Physically based parameterization of cirrus cloud formation for use in global atmospheric models. J. Geophys. Res., 111, D01205, https://doi. org/10.1029/2005JD006219.

Koffi, B., and Coauthors, 2016: Evaluation of the aerosol vertical distribution in global aerosol models through comparison against CALIOP measurements: AeroCom phase II results. J. Geophys. Res. Atmos., 121, 7254-7283, https:// doi.org/10.1002/2015JD024639.

Komurcu, M., and Coauthors, 2014: Intercomparison of the cloud water phase among global climate models. J. Geophys. Res. Atmos., 119, 3372-3400, https://doi.org/10.1002/2013JD021119.

Koop, T., B. Luo, A. Tsias, and T. Peter, 2000: Water activity as the determinant for homogeneous ice nucleation in aqueous solutions. Nature, 406, 611-614, https://doi.org/10.1038/35020537.

Krämer, M., and Coauthors, 2016: A microphysics guide to cirrus clouds-Part 1: Cirrus types. Atmos. Chem. Phys., 16, 34633483, https://doi.org/10.5194/acp-16-3463-2016.
Kuebbeler, M., U. Lohmann, J. Hendricks, and B. Kärcher, 2014: Dust ice nuclei effects on cirrus clouds. Atmos. Chem. Phys., 14, 3027-3046, https://doi.org/10.5194/acp-14-3027-2014.

Lawson, R. P., B. Pilson, B. Baker, Q. Mo, E. Jensen, L. Pfister, and P. Bui, 2008: Aircraft measurements of microphysical properties of subvisible cirrus in the tropical tropopause layer. Atmos. Chem. Phys., 8, 1609-1620, https://doi.org/10.5194/ acp-8-1609-2008.

Lee, J., P. Yang, A. E. Dessler, B.-C. Gao, and S. Platnick, 2009: Distribution and radiative forcing of tropical thin cirrus clouds. J. Atmos. Sci., 66, 3721-3731, https://doi.org/10.1175/ 2009JAS3183.1.

Li, J.-L. F., and Coauthors, 2012: An observationally based evaluation of cloud ice water in CMIP3 and CMIP5 GCMs and contemporary reanalyses using contemporary satellite data. J. Geophys. Res., 117, D16105, https://doi.org/10.1029/ 2012JD017640.

Liu, Z., and Coauthors, 2009: The CALIPSO lidar cloud and aerosol discrimination: Version 2 algorithm and initial assessment of performance. J. Atmos. Oceanic Technol., 26, 1198-1213, https://doi.org/10.1175/2009JTECHA1229.1.

Lohmann, U., and E. Roeckner, 1995: Influence of cirrus cloud radiative forcing on climate and climate sensitivity in a general circulation model. J. Geophys. Res., 100, 16305-16323, https:// doi.org/10.1029/95JD01383.

_, and B. Kärcher, 2002: First interactive simulations of cirrus clouds formed by homogeneous freezing in the ECHAM general circulation model. J. Geophys. Res., 107, 4105, https://doi.org/10.1029/2001JD000767.

, and C. Hoose, 2009: Sensitivity studies of different aerosol indirect effects in mixed-phase clouds. Atmos. Chem. Phys., 9, 8917-8934, https://doi.org/10.5194/acp-9-8917-2009.

, and B. Gasparini, 2017: A cirrus cloud climate dial? Science, 357, 248-249, https://doi.org/10.1126/science.aan3325.

, P. Stier, C. Hoose, S. Ferrachat, S. Kloster, E. Roeckner, and J. Zhang, 2007: Cloud microphysics and aerosol indirect effects in the global climate model ECHAM5-HAM. Atmos. Chem. Phys., 7, 3425-3446, https://doi.org/10.5194/ acp-7-3425-2007.

Luebke, A. E., L. M. Avallone, J. Meyer, C. Rolf, and M. Krämer, 2013: Ice water content of Arctic, midlatitude, and tropical cirrus-Part 2: Extension of the database and new statistical analysis. Atmos. Chem. Phys., 13, 6447-6459, https://doi.org/ 10.5194/acp-13-6447-2013.

- A. Afchine, A. Costa, J. Meyer, C. Rolf, and N. Spelten, 2016: The origin of midlatitude ice clouds and the resulting influence on their microphysical properties. Atmos. Chem. Phys., 16, 5793-5809, https://doi.org/10.5194/acp-16-5793-2016.

Luo, Z., and W. B. Rossow, 2004: Characterizing tropical cirrus life cycle, evolution, and interaction with upper-tropospheric water vapor using Lagrangian trajectory analysis of satellite observations. J. Climate, 17, 4541-4563, https://doi.org/10.1175/ 3222.1.

Madonna, E., 2014: Warm conveyor belts in the ERA-Interim dataset (19792010). Part I: Climatology and potential vorticity evolution. J. Climate, 27, 3-26, https://doi.org/10.1175/ JCLI-D-12-00720.1.

Mauritsen, T., and Coauthors, 2012: Tuning the climate of a global model. J. Adv. Model. Earth Syst., 4, M00A01, https://doi.org/ 10.1029/2012MS000154.

Mitchell, D. L., A. Garnier, M. Avery, and E. Erfani, 2016: CALIPSO observations of the dependence of homo- and heterogeneous ice nucleation in cirrus clouds on latitude, 
season and surface condition. Atmos. Chem. Phys. Discuss., https://doi.org/10.5194/acp-2016-1062.

Möhler, O., and Coauthors, 2006: Efficiency of the deposition mode ice nucleation on mineral dust particles. Atmos. Chem. Phys., 6, 3007-3021, https://doi.org/10.5194/acp-6-3007-2006.

heterogeneous ice nucleation efficiency of mineral dust aerosols. Environ. Res. Lett., 3, 025007, https://doi.org/10.1088/ 1748-9326/3/2/025007.

Muhlbauer, A., T. P. Ackerman, J. M. Comstock, G. S. Diskin, S. M. Evans, R. P. Lawson, and R. T. Marchand, 2014a: Impact of large-scale dynamics on the microphysical properties of midlatitude cirrus. J. Geophys. Res. Atmos., 119, 3976-3996, https://doi.org/10.1002/2013JD020035.

— , E. Berry, J. M. Comstock, and G. G. Mace, 2014b: Perturbed physics ensemble simulations of cirrus on the cloud systemresolving scale. J. Geophys. Res. Atmos., 119, 4709-4735, https://doi.org/10.1002/2013JD020709.

Nam, C. C. W., and J. Quaas, 2012: Evaluation of clouds and precipitation in the ECHAM5 general circulation model using CALIPSO and Cloudsat satellite data. J. Climate, 25, 49754992, https://doi.org/10.1175/JCLI-D-11-00347.1.

Neubauer, D., U. Lohmann, C. Hoose, and M. G. Frontoso, 2014: Impact of the representation of marine stratocumulus clouds on the anthropogenic aerosol effect. Atmos. Chem. Phys., 14, 11 997-12 022, https://doi.org/10.5194/acp-14-11997-2014.

Nordeng, T. E., 1994: Extended versions of the convective parametrization scheme at ECMWF and their impact on the mean and transient activity of the model in the tropics. ECMWF Tech. Memo. 206, 41 pp.

Protopapadaki, S. E., C. J. Stubenrauch, and A. G. Feofilov, 2017: Upper tropospheric cloud systems derived from IR sounders: Properties of cirrus anvils in the tropics. Atmos. Chem. Phys., 17, 3845-3859, https://doi.org/10.5194/acp-17-3845-2017.

Randel, W. J., and E. J. Jensen, 2013: Physical processes in the tropical tropopause layer and their roles in a changing climate. Nat. Geosci., 6, 169-176, https://doi.org/10.1038/ngeo1733.

Rienecker, M. M., and Coauthors, 2011: MERRA: NASA's Modern-Era Retrospective Analysis for research and Applications. J. Climate, 24, 3624-3648, https://doi.org/10.1175/ JCLI-D-11-00015.1.

Riihimaki, L. D., S. A. McFarlane, C. Liang, S. T. Massie, N. Beagley, and T. D. Toth, 2012: Comparison of methods to determine Tropical Tropopause Layer cirrus formation mechanisms. J. Geophys. Res., 117, D06218, https://doi.org/ 10.1029/2011JD016832.

Rossow, W. B., and R. A. Schiffer, 1999: Advances in understanding clouds from ISCCP. Bull. Amer. Meteor. Soc., 80, 2261-2287, https://doi.org/10.1175/1520-0477(1999)080<2261: AIUCFI $>2.0 . \mathrm{CO} ; 2$.

Schiller, C., M. Krämer, A. Afchine, N. Spelten, and N. Sitnikov, 2008: Ice water content of Arctic, midlatitude, and tropical cirrus. J. Geophys. Res., 113, D24208, https://doi.org/10.1029/ 2008JD010342.

Segal-Rosenheimer, M., P. B. Russell, J. M. Livingston, S. Ramachandran, J. Redemann, and B. A. Baum, 2013: Retrieval of cirrus properties by Sun photometry: A new perspective on an old issue. J. Geophys. Res. Atmos., 118, 4503-4520, https://doi.org/10.1002/jgrd.50185.

Shi, X., and X. Liu, 2016: Effect of cloud-scale vertical velocity on the contribution of homogeneous nucleation to cirrus formation and radiative forcing. Geophys. Res. Lett., 43, 6588-6595, https://doi.org/10.1002/2016GL069531.
— — — , and K. Zhang, 2015: Effects of preexisting ice crystals on cirrus clouds and comparison between different ice nucleation parameterizations with the Community Atmosphere Model (CAM5). Atmos. Chem. Phys., 15, 1503-1520, https:// doi.org/10.5194/acp-15-1503-2015.

Spichtinger, P., and M. Krämer, 2013: Tropical tropopause ice clouds: A dynamic approach to the mystery of low crystal numbers. Atmos. Chem. Phys., 13, 9801-9818, https://doi.org/ 10.5194/acp-13-9801-2013.

— K. Gierens, and H. Wernli, 2005: A case study on the formation and evolution of ice supersaturation in the vicinity of a warm conveyor belt's outflow region. Atmos. Chem. Phys., 5, 973-987, https://doi.org/10.5194/acp-5-973-2005.

Stenke, A., V. Grewe, and M. Ponater, 2008: Lagrangian transport of water vapor and cloud water in the ECHAM4 GCM and its impact on the cold bias. Climate Dyn., 31, 491-506, https://doi. org/10.1007/s00382-007-0347-5.

Stephens, G. L., 2005: Cloud feedback in the climate system: A critical review. J. Climate, 18, 237-273, https://doi.org/10.1175/JCLI-3243.1.

Stevens, B., and Coauthors, 2013: Atmospheric component of the MPI-M Earth System Model: ECHAM6. J. Adv. Model. Earth Syst., 5, 146-172, https://doi.org/10.1002/ jame.20015.

Stier, P., and Coauthors, 2005: The aerosol-climate model ECHAM5-HAM. Atmos. Chem. Phys., 5, 1125-1156, https:// doi.org/10.5194/acp-5-1125-2005.

Storelvmo, T., and N. Herger, 2014: Cirrus cloud susceptibility to the injection of ice nuclei in the upper troposphere. J. Geophys. Res. Atmos., 119, 2375-2389, https://doi.org/ 10.1002/2013JD020816.

Tiedtke, M., 1989: A comprehensive mass flux scheme for cumulus parameterization in large-scale models. Mon. Wea. Rev., 117, 1779-1800, https://doi.org/10.1175/1520-0493(1989)117<1779: ACMFSF $>2.0 . \mathrm{CO} ; 2$.

Vaughan, M. A., and Coauthors, 2009: Fully automated detection of cloud and aerosol layers in the CALIPSO lidar measurements. J. Atmos. Oceanic Technol., 26, 2034-2050, https:// doi.org/10.1175/2009JTECHA1228.1.

— ucts catalog. NASA Tech.Rep. PC-SCI-503, 154 pp., https:// www-calipso.larc.nasa.gov/products/CALIPSO_DPC_ Rev4x10.pdf.

Vignati, E., J. Wilson, and P. Stier, 2004: M7: An efficient sizeresolved aerosol microphysics module for large-scale aerosol transport models. J. Geophys. Res., 109, D22202, https:// doi.org/10.1029/2003JD004485.

Voigt, C., and Coauthors, 2017: ML-CIRRUS: The airborne experiment on natural cirrus and contrail cirrus with the high-altitude long-range research aircraft HALO. Bull. Amer. Meteor. Soc., 98, 271-288, https://doi.org/10.1175/ BAMS-D-15-00213.1.

Wernli, H., M. Boettcher, H. Joos, A. K. Miltenberger, and P. Spichtinger, 2016: A trajectory-based classification of ERAInterim ice clouds in the region of the North Atlantic storm track. Geophys. Res. Lett., 43, 6657-6664, https://doi.org/ 10.1002/2016GL068922.

Winker, D. M., W. H. Hunt, and M. J. McGill, 2007: Initial performance assessment of CALIOP. Geophys. Res. Lett., 34, L19803, https://doi.org/10.1029/2007GL030135.

_- M. A. Vaughan, A. Omar, Y. Hu, K. A. Powell, Z. Liu, W. H. Hunt, and S. A. Young, 2009: Overview of the CALIPSO mission and CALIOP data processing algorithms. J. Atmos. Oceanic Technol., 26, 2310-2323, https://doi.org/10.1175/2009JTECHA1281.1. 
- and Coauthors, 2010: The CALIPSO mission: A global 3D view of aerosols and clouds. Bull. Amer. Meteor. Soc., 91, 1211-1229, https://doi.org/10.1175/2010BAMS3009.1.

Young, S. A., and M. A. Vaughan, 2009: The retrieval of profiles of particulate extinction from Cloud-Aerosol Lidar Infrared Pathfinder Satellite Observations (CALIPSO) data: Algorithm description. J. Atmos. Oceanic Technol., 26, 1105-1119, https://doi.org/10.1175/2008JTECHA1221.1.
Zhang, K., and Coauthors, 2012: The global aerosol-climate model ECHAM-HAM, version 2: Sensitivity to improvements in process representations. Atmos. Chem. Phys., 12, 8911-8949, https://doi.org/10.5194/acp-12-8911-2012.

Zhou, C., and J. E. Penner, 2014: Aircraft soot indirect effect on large-scale cirrus clouds: Is the indirect forcing by aircraft soot positive or negative? J. Geophys. Res. Atmos., 119, $11303-$ 11 320, https://doi.org/10.1002/2014JD021914. 